\title{
Abessinische Glossen.
}

Von Enno Littmann.

(Zum Teil nach Kopien von C. Bezold.)

Im Oktober 1906 gab mir C. BEzoLd in Heidelberg Abschriften von Kopien zweier abessinischer Glossare, die er im Jahre 1882 aus Handschriften des British Museum kopiert hatte, mit der freundlichen Erlaubnis sie zu publizieren. $\mathrm{Da}$ ich im August $\mathrm{g} 906$ in Princeton, New Jersey, aus einer äthiopischen Handschrift, die im Besitze von Mr. ROBERT GARRETT ist, ein ähnliches Glossar kopiert hatte, hielt ich es für zweckmässig, dies mit jenen beiden zusammen zu bearbeiten. Ich lege hiermit also die folgenden drei Glossare vor.

I. Aus British Mus., Orient. 2263, foll. 6, a. I-12, b, 2: Tigriña (z. T. Geéez und Amharisch) - Türkisch und Arabisch (im higâzischen Dialekt).

II. Aus MSS. GarRetr, Aeth. VI, foll. I und 142: Amharisch - Arabisch (in ägyptischem Dialekt).

III. Aus Brit. Mus. Add. 16239, foll. $77 \mathrm{a}-85 \mathrm{~b}$ : Ge'ez - Amharisch.

Bei der Edition habe ich mich natürlich genau an die Schreibweise, wie sie in den Kopien vorliegt, gehalten. Verbesserúngen - und deren sind nicht wenige nötig gewesen - habe ich stets als solche gekennzeichnet, auch wo es sich um offenkundige Schreibfehler handelt. Buchstaben, die im Texte in [] gesetzt sind, sind von mir ergänzt. Um die Glossen leichter zitieren zu können, habe ich sie einzeln numeriert. Dabei mussten auch einige Bemerkungen, die nicht eigentlich Glossen sind (vgl. z. B. 
Nr. 693), besondere Zahlen erhalten. Als ich mein fertiges Manuskript, das auf den mir von BEzold übergebenen Abschriften beruhte, noch einmal mit seinen Originalkopien, die er im Jahre 1883 an Herrn Prof. Nöldeke geschickt hatte, verglich, stellte es sich heraus, dass in der $z$ weiten Abschrift einige wenige halbe Glossen ausgefallen waren; in den Fällen hatte ich nur je eine Glosse gezählt, wo in der Tat zwei im Originale standen, jedoch bemerkt, dass hier etwas fehle. Um nun nicht alle Zahlen und die Verweise in den Erklärungen neu zählen zu müssen, habe ich die so wiederhergestellten Glossen als $a$ zu den jeweilig vorhergehenden gestellt; vgl. I 74 a, $236 \mathrm{a}$.

Um I und II auch Arabisten, denen die abessinischen Studien ferner liegen, zugänglich zu machen, habe ich die in äthiopischen Lettern gegebenen arabischen Worte transskribiert. Dabei habe ich, da ja im Aethiopischen ein Verdoppelungszeichen fehlt, in Fällen, in denen für das Arabische eine Doppelkonsonanz in Frage kommt, den betreffenden äthiopischen Buchstaben bei der Transskription in ( ) wiederholt. $\mathrm{Da}$ die arabischen Worte vielfach in sehr merkwürdiger Form erscheinen, habe ich sie stets in ihrer gewöhnlichen arabischen Form wiederholt; damit ist in den meisten Fällen auch bereits die Erklärung des Wortes gegeben. Lange Vokale sind bei der ersten Umschreibung nur durch das Längezeichen wiedergegeben; im Arabischen jedoch sind betonte Längen durch den Circumflex, unbetonte durch das Längezeichen angedeutet.

Ueber die einzelnen Glossare ist noch folgendes $\mathrm{zu}$ bemerken:

I ist von einem Manne aufgestellt, dessen Muttersprache Tigriña war, wahrscheinlich für den Verkehr mit Massaua, ${ }^{x}$ ) wohin noch heute vielfach Kaufleute aus den Tigriña-Gebieten kommen. Auf Massaua weisen zunächst die türkischen Worte hin. Auch die abessinischen Häfen

1) Vgl. Nöldeke in Gölt. gel. Anz. 1886, S. 1015, Anm. 3. 
sind bekanntlich nach der Eroberung Aegyptens durch die Türken vielfach in deren Händen gewesen. Ferner weisen eine Anzahl von Tigrē-Worten, die der Verfasser für arabisch gehalten haben mag, auf Massaua; vgl. Nr. 110, 130, 200, 235, 270. Massaua ist heute zweisprachig, Tigrē und arabisch; das wird es schon seit mehreren Jahrhunderten sein. Endlich aber ist der arabische Dialekt, wie wir ihn hier finden, in Afrika nur an der Küste des roten Meeres denkbar, da er sich eng an den uns bekannten hịgāzischen Dialekt anlehnt. Charakteristisch ist das anlautende $a$ des Imperativs: arqud (Nr. 18, 19); adluul (192, 389); arbut (190, 396); 'aftil. (397) u. a., sogar auch albud (185) und akul (281); vgl. ferner küfíyat (162), kuttân (276). Da-

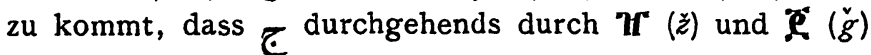
wiedergegeben wird, nie durch $\eta(g)$ wie teilweise in II. Hier sei gleich bemerkt, dass $\boldsymbol{T} \boldsymbol{T}$ und zuweilen im Amharischen mit einander wechseln, dass aber der $\check{z}$-Laut in den nordabessinischen Dialekten nicht heimisch ist; ich glaube daher, dass der Schreiber auch durch $\mathbf{T r}$ den ihm geläufigen $\stackrel{g}{g}$-Laut hat bezeichnen wollen. Zur Inkonsequenz wurde er wohl durch die im Amharischen übliche und auch von ihm geübte Konfusion der Laryngale (einschliesslich'des velaren b) veranlasst. - Für das Arabische in I ist ausserdem charakteristisch, dass, obgleich bei den Substantiven die Formen der Volkssprache ohne auslautende Vokale aufgenommen sind, doch bei den Perfektformen der Verba die Vokale im Auslaute fast immer erhalten sind; vgl. z. B. galasa (17), gassala (292), akaltu (282), sarabtu (284), bultu (288) u. a. Diese Formen brauchen nicht direkt literarisch beeinflusst $z u$ sein; hat ja doch auch Graf LandBekg in Djedda von einem einfachen Beduinenmädchen noch die auslautenden Vokale gehört (Critica Arabica S. 56); vgl. dagegen $\dot{g} \hat{a} b$ (183). Ebenso auffällig wie akul, aluud (s. oben) sind auch die Formen zainani (253) und hažz(ž)amanĩ (257) mit ihrem $a$.

Für den Tigriña-Dialekt des Schreibers ist wichtig, 
dass er noch durchaus kein auslautendes $-;$ bei den Nominalformen kennt; vgl. z. B. hC. (69), 73 k (75), wC\$

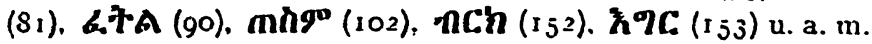

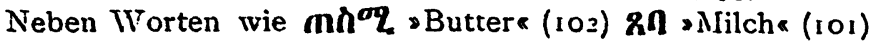
ist besonders auch das Verbum G. Am wissen $(196,303)$ ein sicheres Kennzeichen für das Tigriña. Ausser den wenigen oben angeführten Worten (S. 52), die wohl aus Massaua stammen und vielleicht als arabisch angesehen sind, kommen keine spezifischen Tigrë-TVorte vor; natürlich finden sich aber manche Worte, die das Tigrē mit dem Tigriña gemeinsam hat. Daneben hat der Schreiber auch in einigen wenigen Fällen Ge'ez-Worte und Formen

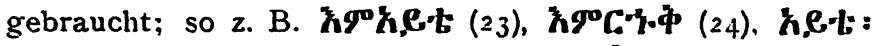

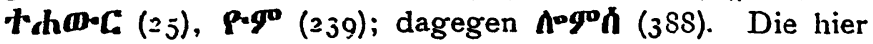
vorkommenden amharischen Worte, meist Pflanzen- und Stoffnamen, sind wohl alle auch ins Tigriña rezipiert, obgleich wir sie nicht immer aus den uns bekannten Texten und Wörterbüchern nachweisen können.

Die Umschreibưng der arabischen Worte ist inbezug auf die Laryngale und das velare $b$, wie gesagt, ganz inkonsequent. Das beruht durchaus auf dem dominierenden Einflusse der amharischen Aussprache, die ja auch in der traditionellen Aussprache des Ge'ez herrscht und daher die eigentlichen Lautverhältnisse des Tigriña und des Tigrẽ für uns so lange verdunkelt hat. Durch eingehende Untersuchungen an Ort und Stelle habe ich feststellen können, dass im Tigrē und Tigriña - sorveit es mir bekannt geworden ist - ' und ', $h$ und $h$ durchaus streng geschieden werden. In $k$ sind allerdings altes $h(h, \tau)$ und $b(\vec{c} \dot{c})$ zusammengefallen, genau so wie im Maltesischen und Neusyrischen des Antilibanon. So ist ja auch altes $s(\boldsymbol{\Lambda})$ und $\xi(\boldsymbol{w})$ in $s$, altes $s(\boldsymbol{g})$ und $d(\boldsymbol{\theta})$ in $s$ zusammengefallen. Ebenso wie ein neues $\xi\left(\tilde{a}^{\prime}\right)$ hat sich aber auch ein neues hl (ந) im Tigriña entwickelt; auch hat das Tigriña einen $\dot{\varepsilon}$-Laut (安). In unserem Glossar nun gehen ' und ' einerseits, $l, l l$ und $b$ andererseits regellos durcheinander; 
Beispiele dafür finden sich auf jeder Seite. Allerdings ist $z u$ bemerken, dass $\tau$ überwiegend durch $\boldsymbol{h}$ wiedergegeben wird. Für $\dot{\tau}$ findet sich of (b). "fi $(k h$ oder $h)$. $\boldsymbol{h}$ $(k)$, $\boldsymbol{l}(h)$ und $\boldsymbol{h}(h)$. Die Umschreibung durch $k$ rührt daher, dass die arabischen Lehnworte mit $\dot{\zeta}$ im 'Tigrē und Tigriũa ein $k$ haben; anlautendes " $\not$ ( Tigriña nicht. Die arabischen Lehnworte mit $\dot{\varepsilon}$ haben im Tigrē und Tigriña ein $\boldsymbol{\phi}(q)$. Daher wird auch hier $\dot{\varepsilon}$ konstant durch $\boldsymbol{\phi}$ wiedergegeben. Von anderen Entsprechungen wäre etwa noch anzuführen:

ט und $b=d$.

$v=s$; nur in kašafa (70) und $\operatorname{ar}(-r))^{3} \bar{a} \bar{s}\left(8_{3}\right)=\dot{s}$.

$\exists=q$ und $g$. In drei Fällen $=k$; das wird fehlerhaft sein $(41,146,176)$.

$$
\begin{aligned}
& ج=\grave{g} \text { und } \check{z} \text {. Vgl. oben S. } 52 . \\
& \dot{J}=d, \text { wie natürlich schon im Arabischen. } \\
& \dot{ث}=t \text {; Ausnahme salž (35). }
\end{aligned}
$$

An dem Glossar I scheinen zwei Hände oder ein Verfasser $z u$ verschiedenen Zeiten gearbeitet $z u$ haben. Von I - 208 steht $\boldsymbol{n}$ zwischen den Aequivalenten, von 209-4 I I steht $\boldsymbol{H}$; ausserdem kommen verschiedene Wiederholungen vor, z. B. 192, 389; 20, 194; 190, 396. Ueber das Alter von I und III kann ich keine näheren Angaben machen.

II stammt aus einer Handschrift, die in der zweiten Hälfte des 18 . Jahrhunderts geschrieben $z u$ sein scheint. Sie enthält I 44 Blätter von ziemlich dickem und rauhem Pergament, $12^{\mathrm{x}} / 2 \times 9 . \mathrm{cm}$. Der Hauptteil besteht aus Psalter (foll. 2 ro. - 125 ro.) und Weddāsē Māryām (foll. 126 ro.142 ro.). Das Glossar steht, wie oben angegeben, auf foll. I und 142 .

Da hier für das Arabische die ägyptischen Monatsnamen angegeben werden, da ferner bei $ج$ die Wieder- 
gabe zwischen $g$ und $\check{g}$ schwankt (vgl. die bezeichnende Glosse 494), so stehe ich nicht an, den hier wiedergegebenen Dialekt als ägyptisch-arabisch zu bezeichnen. Dazu kommen noch Worte wie sibilut (414), ' $\hat{e} s$ »Brote (441), errâgil (451), qusaigar (503), mufaiyá (505), eg-gumi a (519) mit assimiliertem $l$ vor $g$, und die Stellung der Fragepartikel am Ende der Frage $(468,469)$. Bezeichnend ist, dass das $\rightarrow$ überall bleibt und nie in "übergeht. Der Verfasser wird ein abessinischer Mönch gewesen sein, der in einem ägyptischen Kloster lebte. Seine abessinische Heimat war vielleicht Goğğam, da er das $\mathbf{R}, \boldsymbol{\theta}$ beibehält, das die anderen Dialekte, besonders der von Schoa, meist in $\mathbf{m}$ übergehen lassen; vgl. z. B. O7n= (4 1 4), On (422), O': $(423)$, hapq (430). Doch wird sich auch in anderen Dialekten noch manches R. $\theta$ gehalten haben.

Die Transskription der arabischen Worte ist hier etwas konsequenter als in I, wenngleich auch hier 'und ", $h, l i$ und $b$ zuweilen nicht unterschieden werden. In Nr. $44^{2}$ jedoch sind $h$ (in hațab) und $b$ (in khasab) sicher mit Absicht verschieden geschrieben worden.

III ist als ein kleines Specimen äthiopisch-amharischer Grammatik und Lexikographie interessant. Erklärende Bemerkungen $z u$ den Glossen waren bei der $\mathrm{He}$ rausgabe kaum nötig. Es sei hier nur erwähnt, dass auch in diesem Glossar das $\mathbf{h}, \boldsymbol{\theta}$ meist erhalten bleibt; z. B. 200 (605, 617); ang 619, 627 u. ö.; 27ח 674 u. ö. Von grammatischem Interesse ist das begründende postpositive h? (593-601), das äthiopischem $\hbar \hat{n} \sigma 0$ entspricht und mit

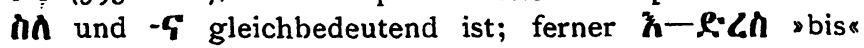
(622-24). Durch Nr. 692 wird auch das Ge'ez-Lexikon um einen neuen Stamm bereichert.

In den mir vorliegenden Abschriften von I und III sehen $\boldsymbol{\eta}$ und $\boldsymbol{\eta}, \boldsymbol{n}$ und $\boldsymbol{n}$ einander öfters ähnlich. Es ist daher möglich, dass ich hin und wieder nicht ganz richtig gesehen und Buchstaben verbessert habe, die es eigentlich nicht nötig hatten. 
lis crübrigt mir noch mehreren Freunden und Lehrern meinen Dank auszusprechen: G. Jacos für einige Bemerkungen zum türkischen Teile $(5,6,8)$, I. Gutur für die lirklärung einer schwierigen amharischen Stelle (No. 693). Tи. Nordeke für eine Anzahl von Bemerkungen zu den arabischen Aequivalenten, die ich durch N. gekennzeichnet habe; vor allem aber $C$. BkzoLt dafür, dass er mir seine mit grosser Mühe und Sorgfalt hergestellten Kopien so freundlich zur Herausgabe anbot.

I.

Tigriña - Türkisch und Tigriña - Arabisch (Ḥigaâzisch).

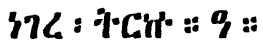

q:: ist wohl zu ergänzen $\mathbf{9}[\boldsymbol{l} \cdot \boldsymbol{n} \boldsymbol{Y} \mathbf{t}]$, und demnach zu übersetzen:

Sprache der Türken und der Araber.

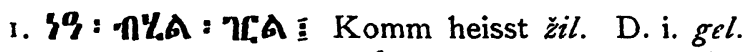

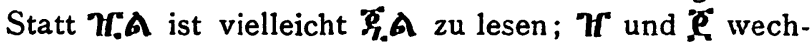
seln ofters. $\bar{l}$ steht für $d^{i}$ und $g^{i}$. Vielleicht ist die Aussprache $g^{i} e l$ beabsichtigt.

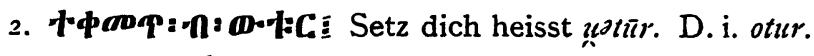

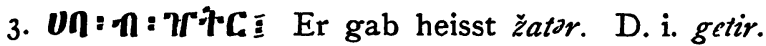

Im Tña steht das Perfekt, im Türkischen der Imperativ. Solche Verwechslungen sind in diesem Glossar sehr häufig. Ueber $z=g$ vgl. Nr. I.

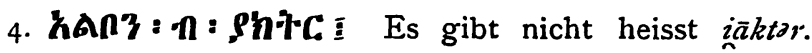
D. i. jok dur.

Das $d$ in $d u r$ hat hier nach dem stimmlosen $k$ seinen Stimmton verloren. Aehnliche Erscheinungen sind im Vulgärtürkischen recht häufig; vgl. $\mathrm{J}_{A C O B}$ in ZDMG 5 , S. 715 .

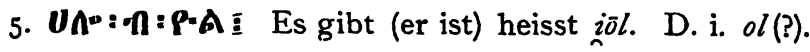
$\mathrm{Zu}$ ol für olur vgl. Nr. 3. Vielleicht ist $P-A$ nur Schreib- 
fehler PA. G. JACOB schreibt mir, er möchte doch eher an jol Weg, Möglichkeit denken; aus der Bedeutung * Möglichkeit « möchte er dann »es gibt« erklären.

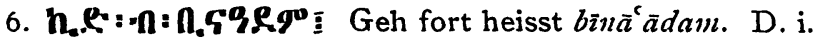
vielleicht bin adam.

G. JACOB schreibt: „Gegen bin »steig zu Pferde (um $z u$ verschwinden) ist an sich kaum etwas einzuwenden; es könnte wie unser »schwimm ab * vulgär geworden sein. Belegen kann ich es nicht." - Ich habe das deutsche "steigen $\approx=$ "weggehen in Berlin gehört.

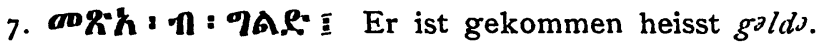
D. i. geldi.

8. h. : : n: RARA II Er ist gegangen heisst daldāl.

G. JACOB schreibt mir: Daldāl wird ein Vulgarismus vielleicht nicht-türkischer Provenienz sein. Bei Redhouse finde ich nur das arabische Jلد د I. a swaying motion; oscillation, vibration; 2. uncertainty, hesitation; 3. agitation, commotion «. I Ich besinne mich nicht das Wort je in einem türkischen Text gelesen $z u$ haben; es muss also wohl selten sein und kommt nicht in Betracht." - Ich hatte an joldāl (Schreibfehler für daldāl) gedacht und dies gleich jolda ol gesetzt; doch $\mathrm{J}_{\mathrm{ACOB}}$ hält das für gekünstelt.

$$
\text { Tigriña - Arabisch. }
$$

9. 39: 10.A : ThA I Komm heisst tảal. D. i. táâl.

Diese Form (Imperativ VI von على) ist aus dem Aegyptischen ( $\left.t a^{c} \hat{a} l a\right)$ und dem Syrischen $\left(t^{c} \hat{a} l, t a^{\prime} a\right)$ genugsam bekannt.

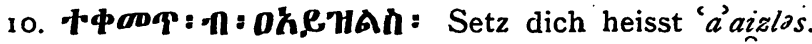
D. i. 'ağlis.

Von den beiden Buchstaben o\% ist der eine zu streichen. Statt $\boldsymbol{T}$ ist $\boldsymbol{O r} z \mathbf{z}$ lesen. Das $\boldsymbol{\ell}$ scheint eine nachträgliche Korrektur zu sein. Die Imperative haben in diesem Glossar fast immer den Anlaut ' $a$, wie im Mekkanischen; vgl. SNouck Hurgronje, Mekkanische Spriclizürter 
und Redinsartcu, S. $3^{8}$. Ein I,eser, dem die Aussprache mit $i$ geläufiger war, mag $i$ als Korrektur eingefügt haben.

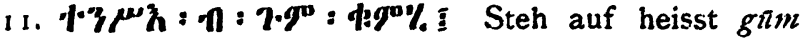
und qnim.

Die Aussprache des $\exists$ als $g$ findet sich in Aegypten, Arabien und Syrien.

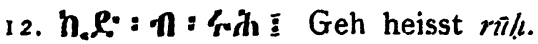

13. h.e.h- : $\mathbf{n}: \mathbf{C} \boldsymbol{h}$ : Ich bin gegangen heisst röl.

Statt $\boldsymbol{C} h$ wird $\mathbf{C H}[\mathbf{1 :}]$ rolutu 2 u lesen sein.

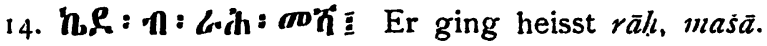

Während in Aegypten und Syrien allgemein misi gesprochen wird, kommt im Hiğâz maša vor; andernfalls müsste man mašs $\bar{a}$ lesen.

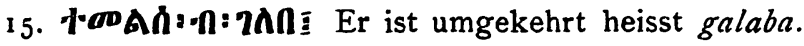
D. i. qalaba (تلب).

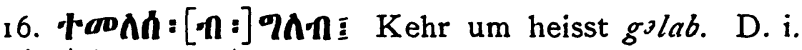
iqlab (أقلب).

Statt $+a b h h$ ist ... i zu lesen.

17. Trhh: :n: +中aDm: žalasa heisst er hat sich gesetzt. D. i. galasa.

Ueber $\check{z}=\grave{g}$ vgl. die Einleitung.

18. UCh : न : hC.?.: : Wecke auf (schlaf?) heisst 'argīd.

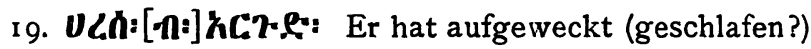
heisst 'argīd.

Statt UC. $\boldsymbol{C}$ ist .. I zu lesen. Ausserdem liegen hier vielleicht Missverständnisse vor. Die Form 'argīd ist natürlich arqud ischlafe; vgl. SNouck Hurgronje, Mckkan. Sprichw. S. 45. In 19 ist der Imperativ gesetzt, wo das Perfekt stehen sollte; vgl. oben Nr. 3. Der Stamm harrasa ist im Tña und im Tè gebräuchlich in der Bedeutung saufwecken«. Naffa' wad 'Otmân aus Gäläb, den ich über das Wort befragte, stellt entschieden in Abrede, dass ULh im Tña "schlafen" bedeuten könnte. Nun haben aber die 
Baseler Evangelien (1866) ein Verbum hCh schlafen «. Statt dessen hat die neue Tigriña-Uebersetzung (Asmara 1900) das gewöhnliche R.中h, wenigstens an 9 Stellen, die ich verglichen habe. Auch DE Vito und Schreiber haben hlh "schlafen \& nicht. Immerhin ist es nicht unmöglich. dass das Verbum hl.h (Géez hloh) »im Kindbett liegen « dialektisch auch in allgemeinerer Bedeutung gebraucht ist.

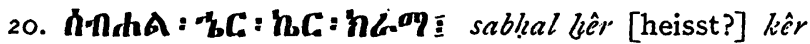
$k a r a ̂ m a \hat{~}$

Das arabische ist natürlich sabâh̆ al-biêr »guten Morgen!e. Karâma ist mir als Bettelruf der Mekkapilger in Nordabessinien bekannt; aber darum handelt es sich hier nicht. Der Text ist hier ganz in Unordnung. Ursprünglich ist wohl der volle Gruss șabâlı al-ļêr wal-kerâma gemeint; vgl. Snouck Hurgronje, 1. c., S. 43. Das TigriñaAequivalent ist ausgefallen; dafür ist kêr als Glosse zu lềr eingedrungen. Im Tigrē wie im Tigriña wird das arabische $b$ wie $k$ gesprochen, trotzdem das Tigriña das mit

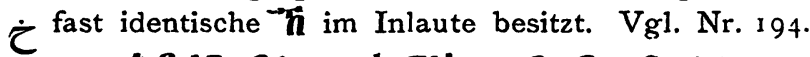

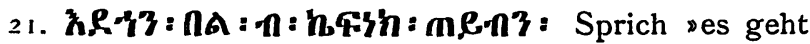
mir gut a heisst kêfonnak tainbon.

Die Tigriña-Worte lassen sich kaum anders übersetzen; aber der Text ist sicher nicht richtig überliefert. Ueber $k \bar{f} f$ inn vgl. NöLdeKe, Bciträge zur semitischen Sprachivissenschaft, S. 6, Anm. 6. In taibon (= taiiziban) hat sich natürlich die Nunation erhalten.

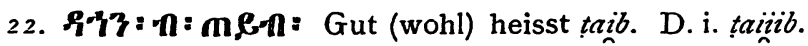
Statt $R+h\}$ ist Rh? (dahán) zu lesen.

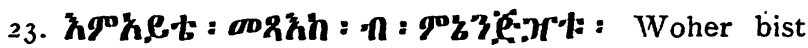

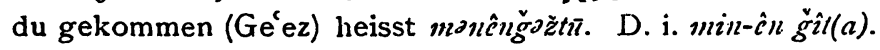

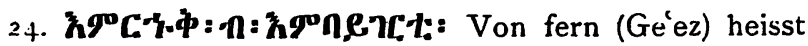
'aınbāịzzitz. D. i. min ba'îd.

In 23 und 24 ist das $\mathbf{P r}$, bzw. Tr: überflüssig und vielleicht späterer Zusatz. Das tī für $d$ könnte auf stimmlose Aussprache im Auslaut deuten; das ist jedoch sehr un- 
sicher, da dieser Uebergang in den arabischen Dialekten. mit Ausnahme des Maltesischen selten ist, und da auch in Nr. $26 d$ im Auslaut steht.

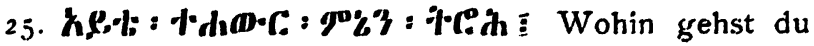
(Ge'ez) heisst manēn taroll. D. i. min-ên terîll.

Das min der Richtung ist sonst bei râlı nicht sehr gebräuchlich; man sagt in Syrien und Aegypten meist wiên oder $f \hat{c} n$ bei râizih (in Syrien auch lawên). Vielleicht liegt hier aber wieder eine der Formangleichungen bei begrifflichen Korrespondenzen vor; vgl. BARTH in Orientalisclue Studien, S. 707.

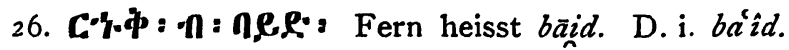

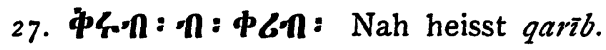

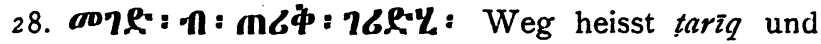
garï.

In garīd könnte vielleicht 'arīd »breit « stecken. Doch glaube ich eher, dass statt $\boldsymbol{\eta}$ besser $\boldsymbol{\eta}$ oder $\mathbf{n} \mathrm{zu}$ lesen ist; dann hätten wir barìd »Wegstrecke».

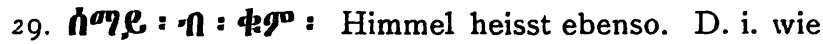
im Tña samiâi

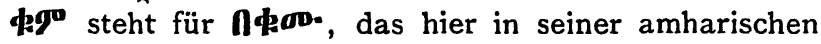
Bedeutung steht, „so wie er ist«; Gurd, Vocabolario, 291: tait quale.

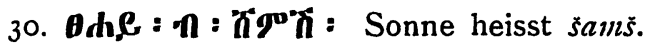

Die Form šanš ist dialektisch auch sonst belegt.

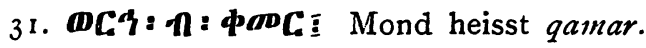

32. hh-h: П\$oo.: Stern ebenso. D. i. kôkab.

33. RavG: नी: hh/n: Wolke heisst sahab. D. i. salıāb.

34 HGF: : : $\mathbf{0 0} \mathbf{m C}:$ Regen heisst matar.

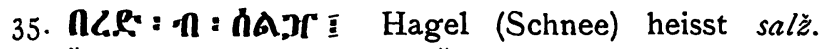
D. i. salgr; vielleicht ist auch palğ beabsichtigt.

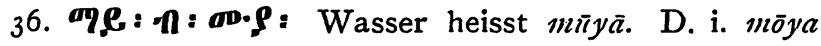
oder mōye; letzteres ist mekkanisch, vgl. SNouck HuRGRONJE, 1. C., S. 47 . 
37. To Rec: -n: 9Cel: Erde heisst 'ärd. D. i. 'ard.

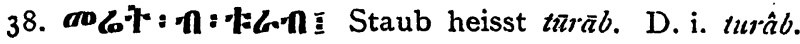

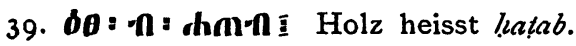

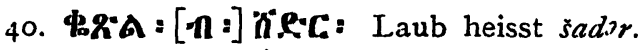

Das arabische نثبر wird gemeint sein. Entweder steht

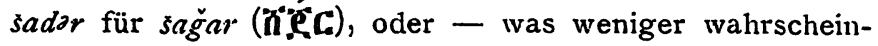
lich ist - wir müssen eine dissimilierte Aussprache šadar im arabischen Dialekte annehmen.

4I. A48: : I: Ch4.A: Borke heisst yokfäl.

Hier liegt wieder ein Missverständnis vor. AhR (Tē) und Ah\%. (Tña) bedeuten: Borke, Rinde, Bast, abgeschuppte Schlangenhaut. N. vergleicht die arabische Wurzel تفل Es wird wohl das Imperfekt yigfal gemeint sein, d. h. ist trocken « (vom Baume). Zum Imperfekt vgl. Nr. 204; zum Wechsel von $k$ und $q \mathrm{Nr}$. 146, 176.

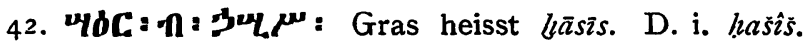

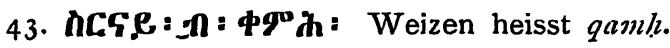

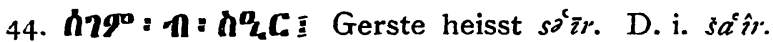

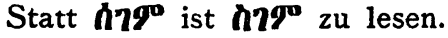

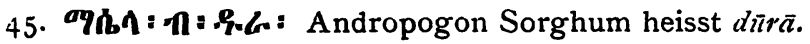
D. i. durāa oder $\overline{d u r} \bar{a}$ (auch $d u r \bar{a}$ gesprochen).

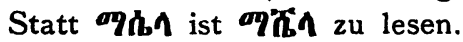

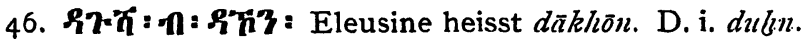

Statt dāghīsa pflegt man meist dāgussā zu sagen; doch ist die Form mit $\xi$ auch bekannt. Das arabische dulun entspricht aber nicht genau, da es eine Hirse-Art ist.

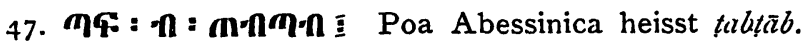

Statt Poa gibt Schweinfurth Eragrostis an. Ein arabisches tabtäb ist mir in dieser Bedeutung nicht bekannt.

48. 9HC: nhC: [-n:] 6-3: Bohne (Vicia Faba L.) heisst fïn. D. i. fül.

49. 9+C: \& tinum L.) heisst 'om(m) uis. D. i. lıummmus. 
50. AnL: 'n ' hïe: I,athyrus sativus I.. (oder Vicia sativa L.) heisst kasare.

Ueber das abessinische sabbaré vgl. Schwrinpurth, s. v. Zu kasarei vgl. Snouck Hurgronje, 1. c., S. 54, Anm. 2. letzterer kennt nur die Form kušsari; die ihm unbekannte Form kasart (vgl. Dozy, s. v. nach BuRtow) scheint durch diese Glosse bestätigt zu werden.

51. नीch3:[नी:] Meh: Linse heisst'äys. D. i. 'adas. gen ist nur Schreibfehler für g/h.

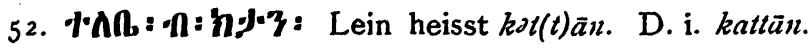

Thß ist das amharische TAM. Heute pflegt man das Leinkraut auf Tña 'antâto's zu nennen.

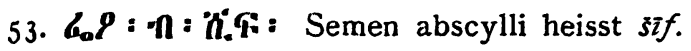

Die Bedeutung von $\boldsymbol{b}_{0} \boldsymbol{P}$ ist nach Guid, Vocabolario. s. v. Gom gegeben. Ein arabisches $\xi_{i} f$ ist mir unbekannt.

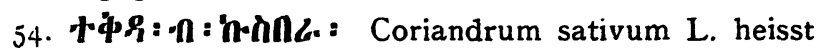
kinsbarā.

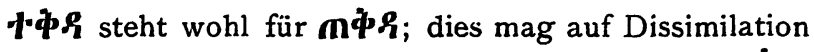
beruhen. Die Tigriña-Form ist nach Schwernfurth $\mathbf{9} \boldsymbol{\phi} \boldsymbol{R}$. Im Arabischen steht kusbura und kusbara neben kuzbura und kuzbara; Dozy hat nur die Formen mit $z$ (vgl. s. v. (كزب).

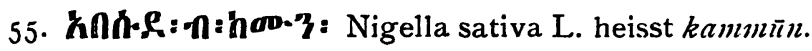

Guidr, s. v. gibt für hחhte. an "specie di menta" (حبة) Im Tigrē sind 'abūsáda und kammīn verschiedene Pflanzen. Schweinfurth gibt für die Formen awosséda und awosséta an Nigella sativa $L$.

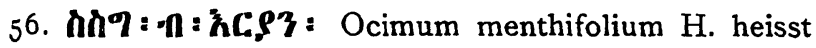
'ar(ri)yān. D. i. er-rỉlıân, vulgär neben er-railâan.

Vgl. Dozy, s. v., wo unter den ريكان-Arten auch Ocimum basilicum genannt wird. Zum amharischen $\mathbf{\hbar C}, \mathbf{P}$ vgl. Praetorius, Amharische Sprache, S. 97.

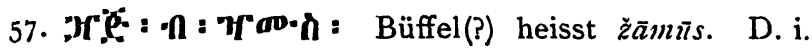
ğāmîs. 
Die Bedeutung des Tigriña-Wortes ist nach dem Arabischen erraten. Vielleicht ist in gemeint.

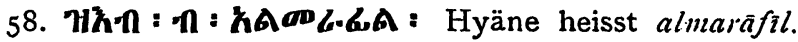

Im Arabischen soll مواذيل eigentlich *Mähne « bedeuten. Die von Dozy (I. 544) bezweifelte Angabe Wrkne's, nach der es »Hyäne" bedeutet, wird durch diese Glosse bestätigt. - N.: "Marafil als sudanesisch-arabischen Namen der Hyaena crocuta weist mir ThORBEcke aus HartaranN, BREHM etc. nach.\&

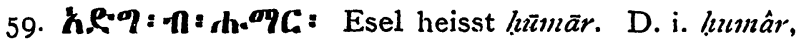
lıimâr.

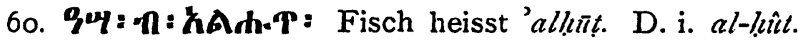

Hiut ist der Name verschiedener Fische; vgl. Dozy, s. v.

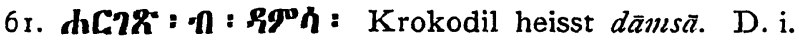
timsầl oder tamsâlu.

62. 7.976: $\cdot \mathbf{n}: \mathbf{n} \boldsymbol{A}$ : Nilpferd heisst bīll.

Aus dem Arabischen ist mir $b i ̄ l l$ sonst nicht bekannt; wohl aber ist $b \partial b_{\bar{e}}$ und $b_{\bar{l}} \bar{l}$ das Ge'ez-Wort für Nilpferd. Nach unserem Glossar wäre dies Wort, das wohl aus dem Aegyptischen stammt, auch in das Arabische gedrungen.

63. Ablob: : : : PC: : Ochse (Stier) heisst torr.

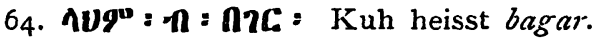

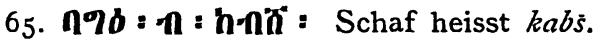

Statt $\mathbf{h} \cdot \mathbf{n} \mathbf{i}$ ist ... $\mathbf{n} z \mathbf{z u}$ lesen.

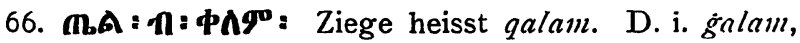
ganam.

Die Aussprache galam kommt dialektisch im Arabischen vor.

67. \$ch\%: : : JrAe: : Haut heisst żald. D. i. ğild.

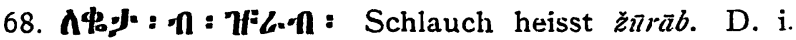
$\grave{g} u r a ̂ b, \grave{g} i r a ̂ b$.

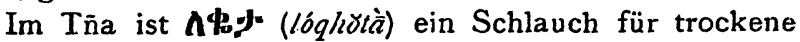

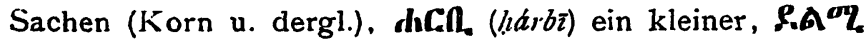
(dällmì) ein grösserer Schlauch für Flüssigkeiten. 


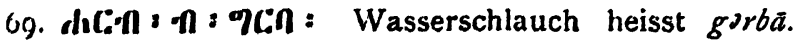
J. i. qirba.

70. A.n\}:-n: hiti.: Palmenmatte heisst kasafai. D. i. basafa.

Im Amharischen heisst $\mathbf{1}$ 3 1. palma; 2. stuoia fatta di foglie di palma (Guirr). Das arabische خصفة, das von $\mathrm{N}$. verglichen wurde, bedeutet $\$ \mathrm{Korb}$, Matte aus Palmgeflechte. - Zur Wiedergabe des 0 durch $\xi$ vgl. 'ar(ro)$s \overline{a s}$, in No. 83 .

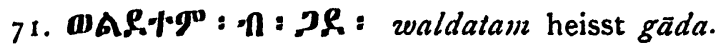

Weder das abessinische noch das arabische Wort ist mit Sicherheit zu erklären. N. denkt bei gãda an gadal, $\tau^{d .}$

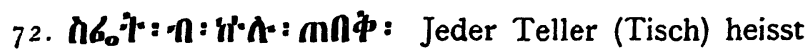
țabaq.

Statt $\boldsymbol{i} b_{0} \%$ 1. h... Im Tña heisst safèt oder safî die als Tisch dienende grosse Schüssel aus Palmgeflecht.

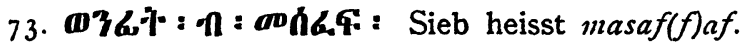

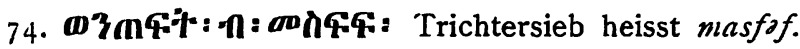

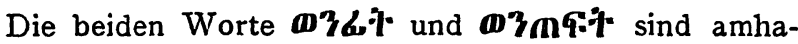
risch; das $\boldsymbol{D}^{3} \mathbf{m}$ F $\%$ wird zum Durchseihen des Hirsebieres gebraucht, es besteht aus einem Trichter, an dessen unterem Ende sich ein Seihtuch befindet. Die arabischen Aequivalente sind ungenau; sie können zu سفسف gehören. N. schlägt vor, minsaf und misfät zu lesen.

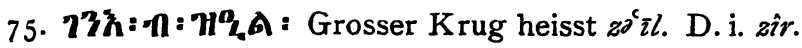
Amhar. gān, Tña gan'î, Tè gani' ist ein grosser Krug, der bis zu 130 Liter enthalten kann. heisst bir.

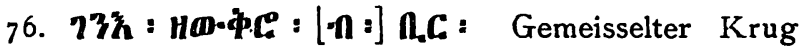

Mit dem "gemeisselten Krug « ist wahrscheinlich ein aus dem Felsen gehauenes Reservoir oder eine Cisterne gemeint. Die Uebersetzung bir (بنَ) ist allerdings etwas zu allgemein. 


\section{7.}

In dieser Glosse scheinen zwei zusammengefallen zu sein.

a) DFC: : П : ZC: [:] Krug heisst gìr. D. i. vielleicht gar [ra].

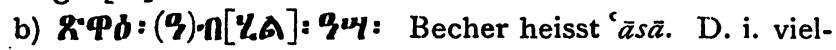
leicht $k \bar{a} s$.

Diese Erklärungen sind allerdings sehr unsicher. N. denkt an zìr (für $g \bar{\imath} v$ ) und țāsa (für ' $\bar{a} s \bar{a}$ ); das ist wahrscheinlicher.

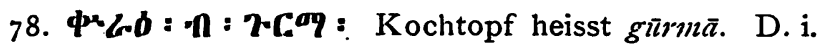
burma.

中. bod ist ein Topf aus Ton, der zum Kochen benutzt

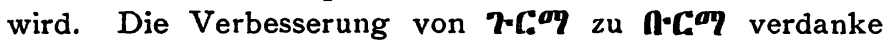
ich $\mathrm{N}$.

79. U⿴囗: - : KShC: Feuer heisst 'on(n) ăhar. D. i. en-nār.

Statt U⿴囗 ist hW- oder $\boldsymbol{h} \boldsymbol{h}$ zu lesen.

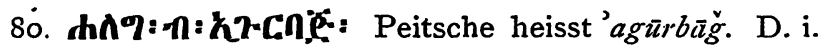
al-quvbầg.

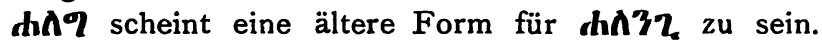
Statt قرباج zرباج zu sagen.

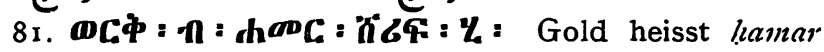
und sarīf.

Der Glossator hat hier die Attribute des Goldes "rot " ('allmar) und »kostbar « auf das Gold selbst übertragen.

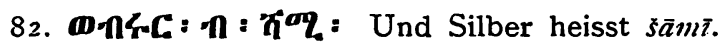

Das Attribut $\xi_{a} a m \imath z$, das hier auf das Silber übertragen ist, wird von den Damascenerklingen stammen. Das mag schon im Arabischen der Fall gewesen sein.

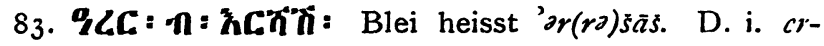
nușâs.

$\mathrm{Zu} \omega=\dot{s}$ vgl. No. 70 .

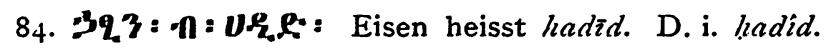

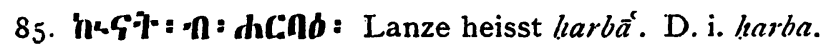


86. $\dddot{h} \cdot 1 \cdot A: \cap \cap: T r g^{\circ} \rho:$ Krummer Dolch heisst žam- . (imi) jar. D. i. ğambiya.

Das Wort جنبية ist in Mekka bereits zur Zeit des Ibn Bațûța gebräuchlich gewesen. In $7 \mathcal{F}^{\circ} \rho$ ist entweder ein $\boldsymbol{n}$ ausgefallen, oder eine Lesung zammîya, mit assimiliertem $b$ ist beabsichtigt.

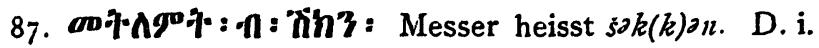
sikkin.

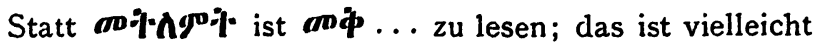
nur ein Schreibfehler. Das Wort ist amharisch; im Tña und Tẽ sagt man statt dessen malāșé.

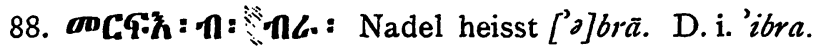

89. б0中h : П中oD.: Scheere heisst ebenso. D. i. maqass.

Im Tña steht natürlich maqas(s) statt maqașs.

90. 6.7A: П: dheR: Faden heisst haid(?). D. i. Lait.

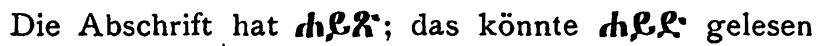
werden. Vielleicht aber steht $\boldsymbol{R}^{*}$ hier für $\mathbf{T}$.

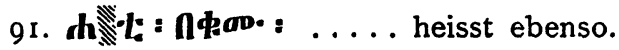

B. hat als zweiten Buchstaben des undeutlichen Wortes $z w e i f e l n d$ ein $\boldsymbol{k}$ angegeben.

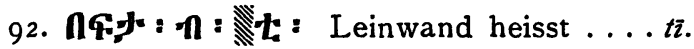

Vielleicht ist auch im Arabischen baftā gemeint.

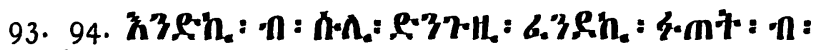

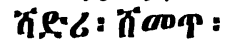

Hier sind wohl drei Glossen von einander zu scheiden.

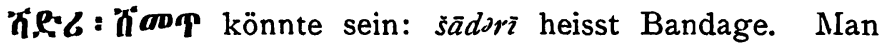
könnte an ثدوذ; denken; vgl. Dozy, s. v. Es handelt sich um Zeugsorten.

95. ПC: žnkk. D. i. ğûu.

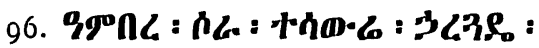

Der lext ist hier nicht in Ordnung. Das amharische Wort Kl.37. heisst I. verde; azzurro, 2. musco che si forma sulla superficie dell' acqua (G.). Legt man die zweite 
Bedeutung zu Grunde, so wäre 'ämbara wohl = 'anbar. - Die Worte hls: $\boldsymbol{H} \boldsymbol{h} \mathbf{0} \cdot \mathbf{6}$ sind wohl aus anderem $\mathrm{Zu}$ sammenhang hierher geraten.

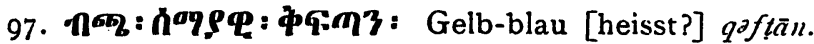

Vielleicht ist die Farbe hier auf das Kleidungsstück übertragen.

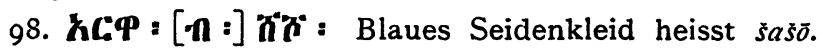
D. i. sâs.

Ueber 丸C.9 vgl. Guidi, s. v.; über ثماث Dozy, s. v. 99. HCC: П中ov.: Gürtel heisst ebenso. D. i. zunnâr.

Das Tña-Wort könnte ebensogut auf żınấr wie auf zinnลâr zurückgehen.

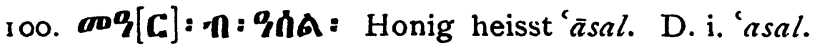
ror. 0n: $\mathbf{n}: \mathbf{\Lambda} \mathbf{3}$ : Milch heisst laban.

102. mingo : $\boldsymbol{n}: \mathbf{n g}^{\circ} \mathbf{3}$ : Butter heisst saman. D. i: samn oder samun.

103. Ng: n: hnUg': Fleisch heisst 'ol(l)aham. D. i. cl-lalım.

104. h.RC: -n: hC:A : Senf heisst kardal. D. i. bardal. 105. \$326: : n: 6.m.[C] : [Ungesäuertes] Brot heisst fațīr.

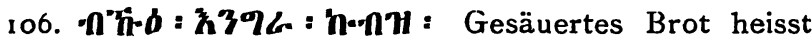
kǖbz. D. i. bü̆bz.

Das Tña-Aequivalent ist $\boldsymbol{n} \boldsymbol{h} \mathbf{h} \cdot \mathbf{h}: \mathbf{\hbar 3 2 6}$ zu lesen. Heute sagt man meist $\boldsymbol{n h h . \boldsymbol { \phi } ; ~ v g l . ~ P r a E r o r i u s , ~ T i g r i n ̃ a - ~}$ Sprache, S. 111.

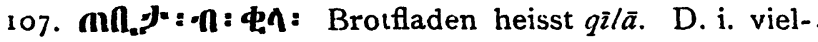
leicht qêla.

Hier scheint eine Verwechslung vorzuliegen, falls der Text nicht verderbt ist. Das arabische qêla bedeutet in Mekka ,Einladung, Picknick u. s. w.«; vgl. SNouck HurGRONJE, 1. c., S. $85 \mathrm{ff}$.

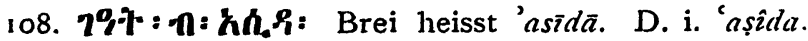

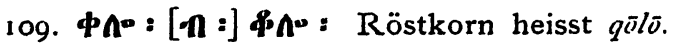


Hier liegt wohl eine Verwechslung zwischen Substantivum und Verbum vor. Auch ist der Text nicht ganz sicher. Vgl. קخi ,قلية ,

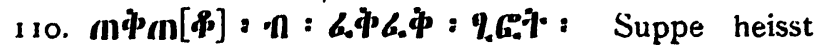
faqfaq.

Vielleicht sind auch hier Substantivum und Verbum verwechselt; faqfaq wird vom Brodeln des Suppenkessels gesagt. $\mathbf{m} \mathbf{\phi} \boldsymbol{\phi} \boldsymbol{\phi}$ ist das Tña-Wort, G.6.\% das Të-Wort für eine dicke Suppe aus Korn oder aus Reis.

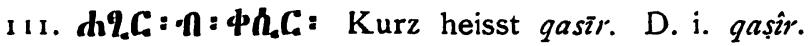

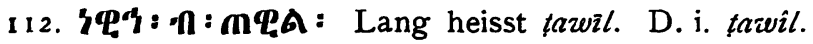

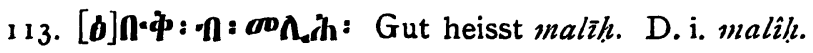

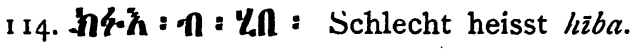

Das arabische Wort ist verderbt; vielleicht ist es = babîs. N. denkt an baiba.

1 15. $\boldsymbol{h} \boldsymbol{h} \boldsymbol{Q}: \cdot \boldsymbol{n}: \boldsymbol{h}[\boldsymbol{h}] \boldsymbol{n}:$ Lügner heisst ka[ddā]b.

Ich ergänze $\boldsymbol{h}$, nicht $\boldsymbol{H}$, wegen der in Mekka üblichen Form; vgl. Snouck Hurgronje, S. 35.

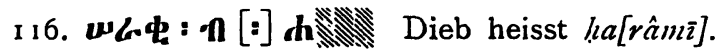

h ist natürlich $z u$ dibo $\boldsymbol{q}_{\mathbf{c}} \mathrm{zu}$ ergänzen.

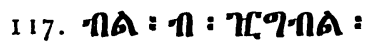

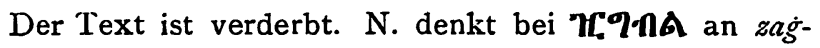
bar "Salbei" (eine Art Origanum). Aber 'nA als Name einer Pflanze ist mir aus abessinischen Dialekten nicht bekannt. Im Amharischen heisst nA 》Wurm«.

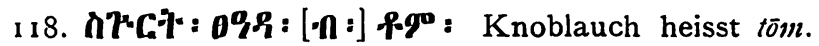
D. i. tĥ̀m.

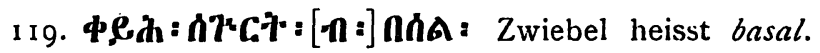
D. i. bașal.

Statt $\mathbf{n} \mathbf{T} \mathbf{C} \boldsymbol{T}$ ist $\boldsymbol{n} . . \mathrm{zu}$ lesen.

1 20. ACAl6: : : 6.A6.ム : Pfeffer heisst falfal. D. i. filfil.

Die beiden Pflanzen entsprechen sich nicht genau. 
Der hier genannte abessinische Pfeffer $(b \ddot{a}, \cdot b \ddot{a}, r \bar{c})$ ist Capsicum Abessinicum $\mathbf{R}$.

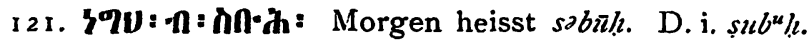

Die Aussprache subulı wird für Mekka bezeugt von SN. Hurgr., S. 99.

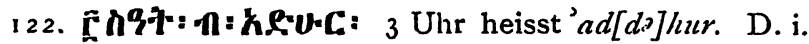
ad-duhuur.

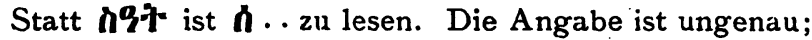
ebenso 123 .

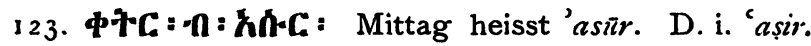

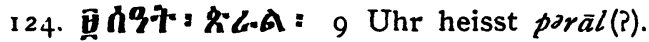

N. schlägt vor zawāl statt perāl zu lesen.

: 125. hCh: न: hAm中l-n: Abend heisst 'almaqarab. D. i. al-magrib.

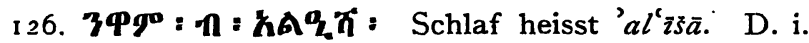
$a l-i \xi \xi \bar{a}$.

Das Versehen ist leicht erklärlich.

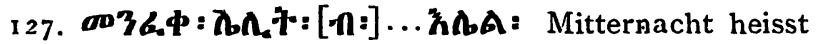
...'allēl. D. i. ...el-lêl.

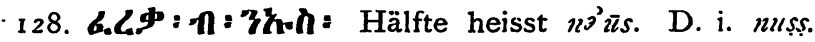

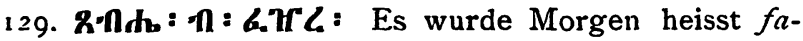
żara. D. i. fağara.

130. a09А und 'annāhar. D: i. (Tigrē) máal und en-nahâr.

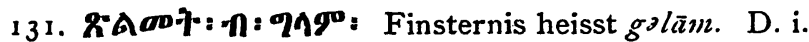
zุalâm.

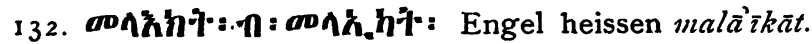
D. i. malầikat.

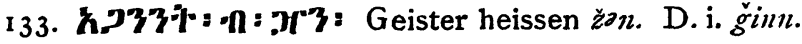

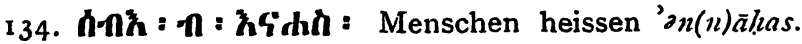
D. i. en-nâs. riğâl.

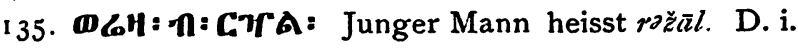




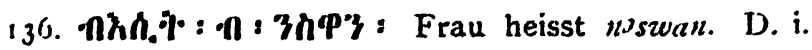
"iszuâ".

In 135 und 136 steht im Abessinischen der Singular, im Arabischen der Plural.

137. $1193:$ : : ILC: Knabe heisst saqir. D. i. sagir.

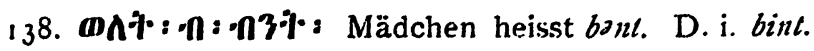

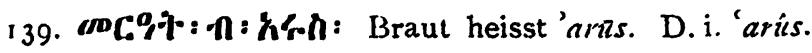
'ăgùza.

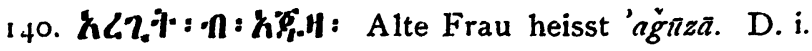

Zur Form 'ăğìa vgl. JACOB, Geschichte des Schattenthcaters, S. 49, Anm. 1.

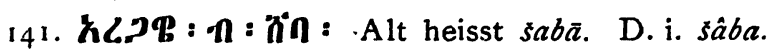

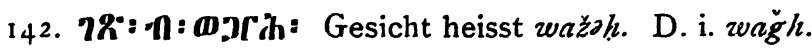

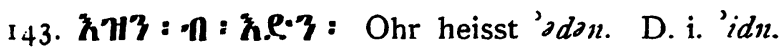

144. RT-C: : : : hdhC: Haar heisst sahar. D. i. šáar.

145. R:hgo: n: :.q3: Bart heisst dogan. D. i. daqan.

146. hhe:- $\mathbf{n}:$ LhnF: Hals heisst rakabat. D.i raqabat.

In der Abschrift B.'s scheint "inhe. zu stehen; das wäre auf jeden Fall in $\mathbf{h} . \mathrm{zu}$ verbessern. Lhht ist Fehler für $\mathbf{L} \boldsymbol{\phi} .$.

147. R.L7: [नी:] he:C: Brust heisst șador. D. i. șadir.

148. HПz: : : 3F:k: : zabān heisst ebenso.

Im Tña bedeutet zäbān »Rücken, Bergrücken« (vgl. Ge'ez R.nC, engl. ridge); im Ge'ez ist zaman, im Tẽ $z \ddot{a}-$ bän, im Tña zäbän und zämän »Zeit«. Die Bedeutung \Rücken« ist hier sicher gemeint, wie sich aus dem Context ergibt. Dem Glossator hat hier das arabische zamân »Zeit« vorgeschwebt, das aber mit zäbän, zämän gleichbedeutend ist.

149. hC.N : नी: ПT\} : Bauch heisst batn.

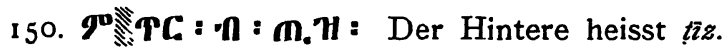

Das Tña-Wort wird monch zu lesen sein.

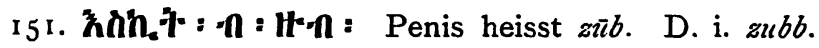


152. ACh: $\cdot$ : LhnF: Knie heisst rakabat. D. i. mkbat.

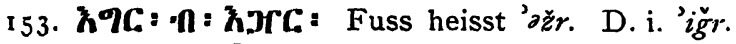

154. h90 $\boldsymbol{n}: \boldsymbol{n}: \boldsymbol{h}=\boldsymbol{n}:$ Vulva heisst kius. D. i. kuss.

Es ist bezeichnend, dass in 151 und 154 die literarischen Worte gewählt sind, nicht die Worte der Volkssprache tîn und $g^{0} \mathbf{T} G$.

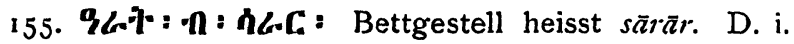
sarîr.

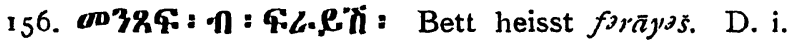
farâyis.

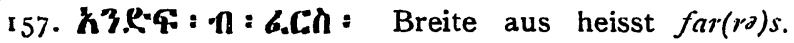
D. i. farris.

Statt $\mathbf{h} \mathbf{3} \cdot \mathbf{q}:$ ist $\ldots \mathbf{R} \cdot \mathbf{z u}$ lesen.

158. 37d : -n: गrA: Fell heisst žal. D. i. ğild.

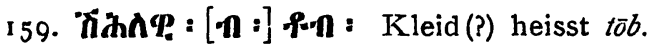

Das Tña-Wort ist mir nicht bekannt.

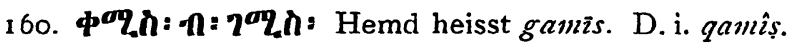
sirzuâl.

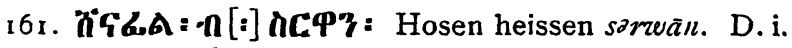

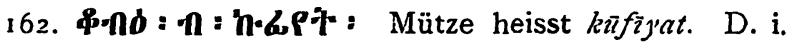
kinfijat.

Nach SN. Hurgr., S. 41, Anm. ist die knfijjch 》die zylinderförmige, aus indischem Rohr geflochtene, mit vielfarbiger Seide oder Kattun durchstickte Mütze, um welche die 'imāmah herumgewunden wird«. Das entspricht auch dem Tña-Worte $\boldsymbol{\Phi} \cdot \boldsymbol{f} \boldsymbol{\delta}$ am ehesten. Die syrische und ägyptische käffìye (das Kopftuch) heisst im Hiğâz șlinâdeh. Ueber \$.nd vgl. noch Gurdr in Bezold, Kebra Nagast, S. XXVI s. v.

163. optcoh : [n:] mhe: Kopfkissen heisst ma$\operatorname{kad}(d) a$. D. i. makadda oder mibadda.

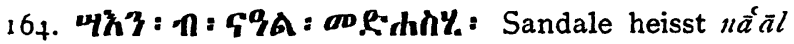
und madluas. D. i. na'l und madâs.

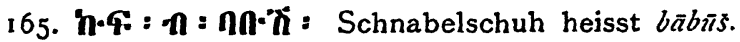

Das Wort h-F: ist eher amharisch als nordabessinisch; 
vgl. GuinI, s. v. Der Glossator hat jedenfalls بابوش gehört, nicht بابوج; Dozy (s. v.) gibt jedoch letztere Form als die gewöhnlichere an.

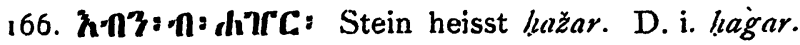

167. $\mathrm{n} \%: \cap: 00 h\}$ : Haus heisst makān.

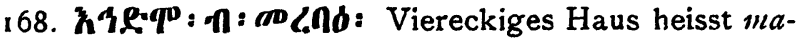
$\operatorname{rab}(b) \bar{a}^{c}$. D. i. murabbac.

Das viereckige abessinische Haus heisst heute im Tña hodino, im Tè nollos. Das arabische Wort marabba wird heute nur von europäischen Häusern gebraucht.

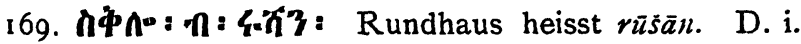
rôsan.

Der abessinische Rundbau (von den Italienern tocul genannt) heisst im Tña und Tē gewöhnlich $s \partial q^{\nu} l \bar{o}$. Das aus dem Persischen stammende rôsan wird im Arabischen von verschiedenen Hausteilen gebraucht. Ueber die abessinischen Häuser vgl. u. a. meine Ausgabe der Heldentaten des Dom Christoph da Gama, S. ror.

170. Padi: मी: hA-nh: Katze heisst albos. D. i. albiss oder al-bass.

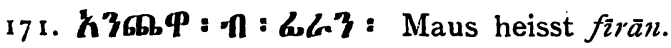

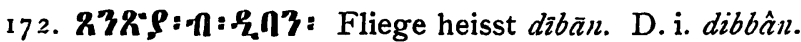

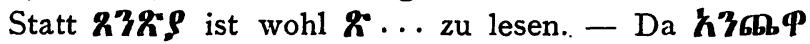
und $\mathbf{R 3 9}$ sowohl singularisch wie kollektivisch gebraucht werden, steht im Arabischen hier der Plural, obwohl der Glossator wahrscheinlich den Singular beabsichtigt hat.

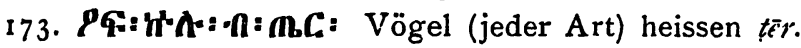

174. RCư: •ी : Tr'ge: Huhn heisst žadād. D. i. da$\grave{g} \bar{a} \check{g}, \dot{g} \bar{a} \check{g}$. al-fîl.

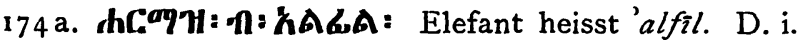

175. K3חh: : : hhe: : Löwe heisst 'asad.

176. Une: n: HC.e: Affe heisst kuard. D. i. qird. Hier steht $k$ für $q$ wie in No. 146 . 


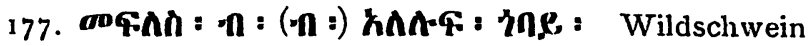
heisst 'alalinf. D. i. liallîf.

Das arabische Aequivalent für ine »Büffel« ist ausgefallen.

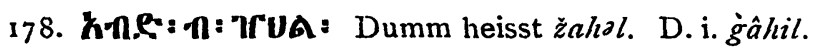

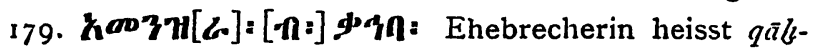
bā. D. i. qahba.

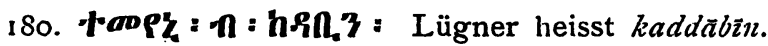

Statt Fompz ist .. P. zu lesen.

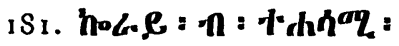

Diese Glosse ist, wie sie dasteht, amharisch-Tigriña.

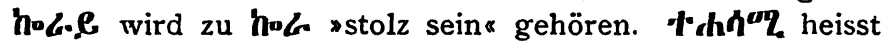
nach DE VIro restio a ricevere «. Es werden aber wohl $z$ wei arabische Aequivalente ausgefallen sein.

182. C1:b : न: mb-n: Recht heisst tayab. D. i. taijib. I83. Un: नी: 1r'न : Er gab heisst zab. D. i. ğâb (er brachte). 'addînī.

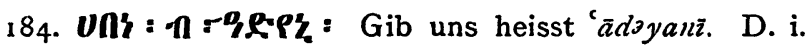

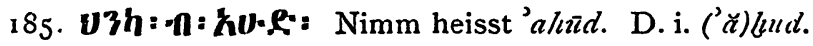

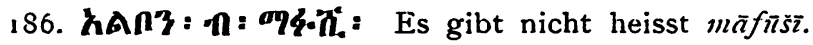
D. i. $m \bar{a}-f \hat{i}-\bar{s} \bar{i}$.

187. Un०: $n:$ 6。: Es gibt heisst $f \hat{i}$.

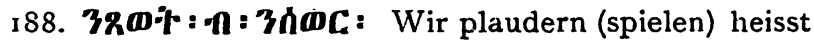
nas(s)a(u)war. D. i. wohl nișsauwar.

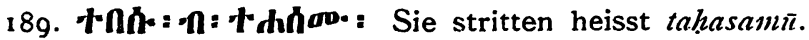
D. i. taל̧âșamiz.

Statt +hh- ist $\boldsymbol{+} \boldsymbol{n} \boldsymbol{h} \boldsymbol{h} \mathbf{z u}$ lesen.

190. H[I] : [नी:] hCA-P: Schliess heisst 'arbint. D. i. arbuț.

Das Verbum H $\boldsymbol{W U}$ scheint heute im Tña nicht mehr gebräuchlich zu sein; vgl. Ge'ez $11 \%$ h und Amhar. $11,3$.

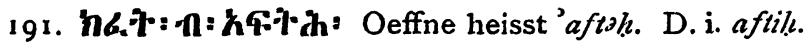




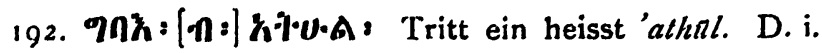
adbul.

Bemerkenswert ist der Uebergang $d>t$ vor dem stimmlosen b. Vgl. unten No. ${ }^{889}$.

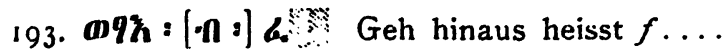

Das arabische Aequivalent wird wohl 4.\% ( fiut) sein sollen. Das könnte "geh vorbei \& bedeuten. Meistens heisst füt aber stritt ein «; dann hätte der Glossator »hineingehen « und shinausgehen verwechselt.

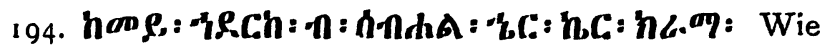
hast du die Nacht zugebracht heisst sablual bēr kïr ksrā$m a \bar{a}$. D. i. șabâll al-lı̂er. Vgl. No. 20.

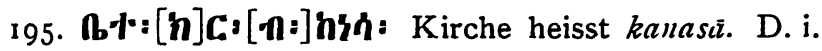
kanîsa.

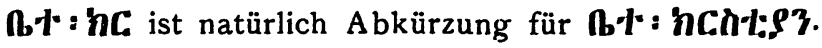

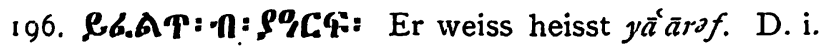
yacrif.

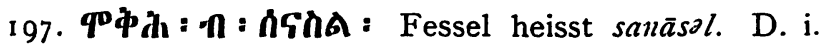
sauâsil.

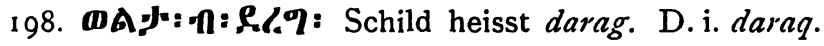

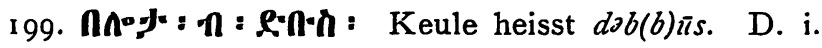
dabbîs.

Das Wort חn+o ist amharisch; vgl. Guidr, s. v. Statt e:n-n ist vielleicht $\boldsymbol{\ell} . . z$ zu lesen. Vgl. aber die dissimilierte Form $\boldsymbol{e}^{\mathbf{n}} \boldsymbol{n} \cdot \boldsymbol{n}$, Dillmann, Sitzungsher. Berl. Akad., 1884, S. 1014, Anm. 3.

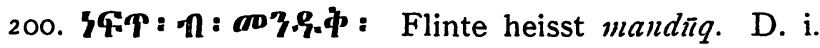
mandîq.

Flinte heisst im Tè heute mandîq. Das ist das ara-

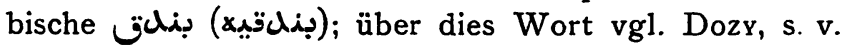

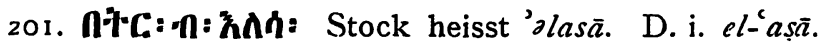

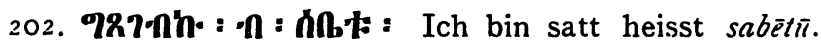
D. i. sabictu.

Das erste $q$ ist $z u$ streichen. 


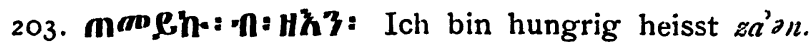
D. i. ğ $\bar{u}^{c} \hat{a} u$.

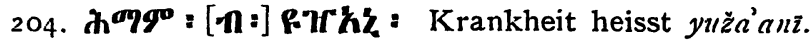
D. i. $y \ddot{n} \stackrel{\text { ğ }}{a} n \bar{t}$.

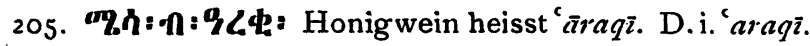
Statt $\sigma \mathbf{q}$ ist $\cdot \boldsymbol{h}$ zu lesen.

206. $\boldsymbol{\Lambda} \boldsymbol{\Phi}: \boldsymbol{\cap}: \mathbf{n} \cdot[\mathbf{H}]:$ Hirsebier heisst bizzā.

Statt $\boldsymbol{\Lambda} \boldsymbol{\Phi}$ ist $\boldsymbol{\Pi} \cdot \mathbf{z u}$ lesen.

207. 3h.e: : n: 3h.7ic: Lass uns gehen heisst nokizer. Die arabische Form ist schlecht überliefert. Am ehesten wird 3hC: (nəkrəz) zu lesen sein. Das wäre nuluruğ.

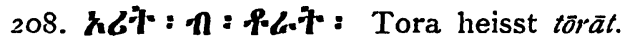

209. Rq. : H:HAC: David (d. i. Psalter) heisst zabitr. 210. 032А:H:ћ3,JCA: Evangelium heisst 'onžsl. D. i. 'inğill.

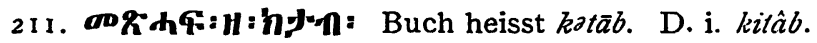

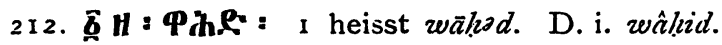

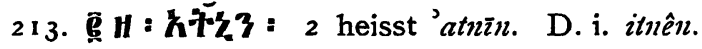
214. I H : †クJ: 3 heisst talātā. D. i. talâta. 215. ํㅐ 보 : 4 heisst 40. D. i. (Tña) 'arbóa ('arbcia). 216. E H : : 5 heisst 50. D. i. (Tña) hamsā (bamsa). 217. $\mathbf{z} \|: h_{\mathbf{s}} \mathbf{y}: 6$ heisst $\operatorname{sit}(t) \bar{a}$. D. i. sitta.

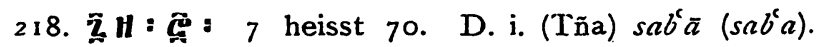

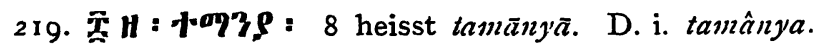

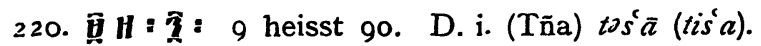
221. I H: hî́l l. : 10 heisst 'ašarā. D. i. 'asara.

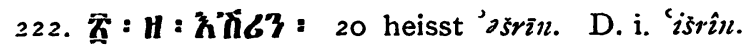

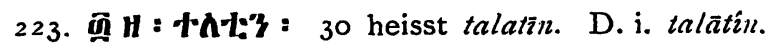
Statt $+\mathbf{n t :} \mathbf{z}$ ist . $\mathbf{1}$.. zu lesen.

224. 펵 H: KC:003: 40 heisst 'arbo'zn. D. i. 'arba' în.

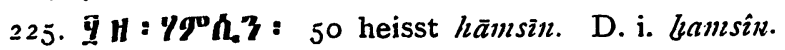
226. 害 $\mathrm{H}: n+13: 60$ heisst sat(t)an. D. i. sittin. 


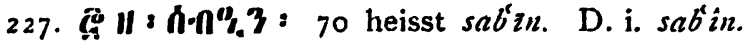

228. Tी $\|: \cdot \cdot a \eta \% 3:$ : 80 heisst tamanzin. D. i. tamänin.

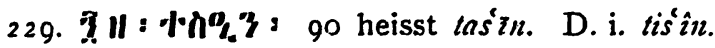

Statt $\uparrow \hbar \%, 3$ wird $¥ \ldots$ zu lesen sein. Das Versehen rührt daher, dass man im Tña wie im Geez $\operatorname{tos}^{c} \bar{a}$ und $\operatorname{tas}^{2} \bar{a}$ sagt.

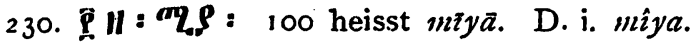

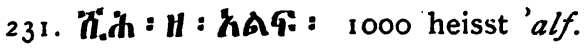

232. Q : II: AH : 10000 heisst lok". D. i. likk.

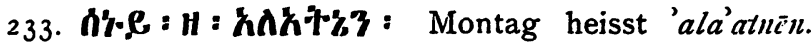
D. i. al'itnên.

Vielleicht ist aber in dem $z u$ grunde liegenden arabischen Dialekte auch 'atıên gesprochen; vgl. oben No. 213 und den Anlaut des Imperativs, No. 10. SN. Hurgr. (S. 69) hat aber itnlēn.

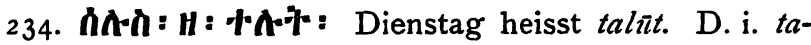
lâta, oder tâlit(?).

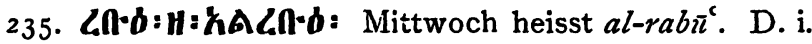
$a r-r a \hat{b} i^{c}$ (?).

Es ist möglich, dass der Glossator einfach die abessinische Vokalisation auf die arabischen Formen übertragen hat, oder dass man in Massaua auch im Arabischen die abessinischen Formen gebrauchte. Andernfalls müsste man annehmen, dass im Arabischen hier die Ordinalzahlen gebraucht wurden statt der Kardinalzahlen; doch das ist sehr unwahrscheinlich.

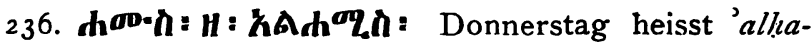
mīs. D. i. al-ḩamîs.

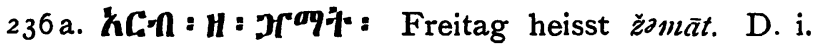
ğuñat.

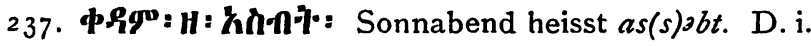
as-sübt.

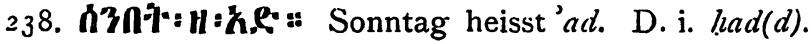


239. P.go: H[:] hAP.qo: Heute (Ge'ez) heisst 'alyōm. D. i. al-yôm.

240. Bnh: H[:] nh'6.7:: Morgen heisst bakurat. D. i. bukrat.

Hier wird wie öfters in der Schrift das « zum k-Laut

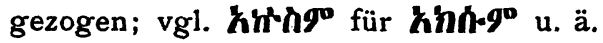

241. T-a9A:H: $\mathbf{h}^{\circ} \boldsymbol{\lambda}$ : Gestern heisst luans. D. i. 'ams.

242. hav-3:H: hoonp.go: Woche heissț kamalajōm.

In dem arabischen Worte könnte kamal al-yôm oder etwa kamấl al-'aiyâm stecken. N. schlägt jedoch vor كها zu lesen, d. i. "heute nach einer Woche«.

243. OCA: H: H9C: Monat heisst sacār. D. i. sah(a)r. 244. 9007: H: hGK: Jahr heisst sanä. D. i. sana. 245. ha07: : : :

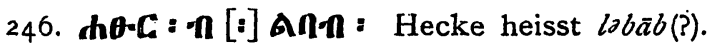

Das arabische Aequivalent ist verderbt. Man könnte 1. hAП-П $(a l-b \hat{a} b)$ lesen und annehmen, dass hier bereits das folgende Wort voraufgenommen ist, oder 2. hn-n $(k \bar{e} l a b)$ lesen und darin das Tigrē-Wort für "Hecke, Einfriedigung « sehen.

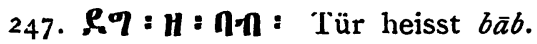

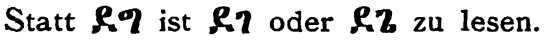
ğîuā.

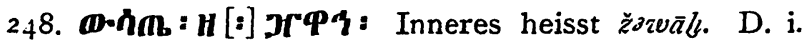

249. arhhA : H: g0 h3 : Wetzstein heisst moson(n). D. i. misann.

250. adnQ : H : hA00-h : Rasiermesser heisst 'almits. D i. al-minis.

25 1. hUn:H: గi̊: Wetze es heisst $\operatorname{san}(n) \bar{o}$. D. i. sinnō. 252. 19:H:He3: Rasiere heisst $z a(i) y \partial n$. D. i. zaijin.

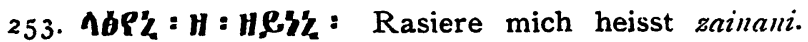
D. i. zaijin(a)nī.

254. 199.: H: H:Y?: Barbier heisst za(i)yān. D. i. zaij'ân. 


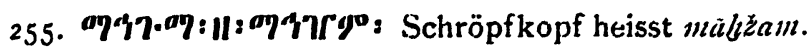
D. i. miligam.

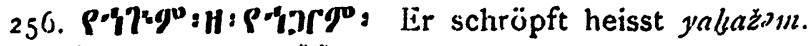
1). i. yalığim, oder yulıăğgim.

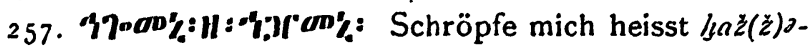
mant. D. i luăğim(a)mi.

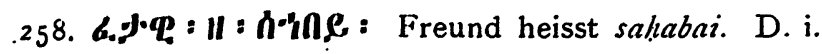
sâlıibi.

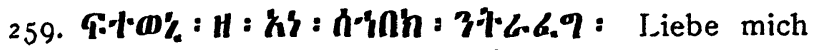
heisst 'ana salıabak noträfag. D. i. 'ana șâhlibak nitrâfaq. 260. 6.j.中P: H: L.6\%: : Sein Freund heisst rafign. D. i. rafíqui.

26r. GF'hA: H : -nnerh : PKAF: Er schwört heisst bolais ya'alaf. D. i. bil-aiš(?) yalulif.

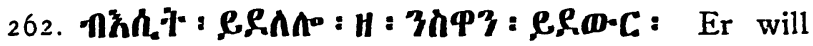
eine Frau heisst nəswān yəda(u)war. D. i. niswân idauzir.

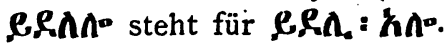

263. F6.1:R:H: T.CoS: Willst du heisst torada. D. i. terîd.

Am Ende des ersten Wortes ist \&, am Ende des zweiten $\boldsymbol{\ell}$ zu lesen.

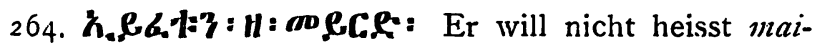
rd. D. i. ma-irîtd.

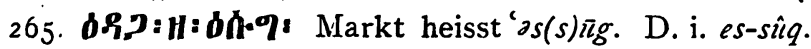

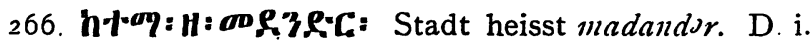
bandar(?).

mof3e:c ist wohl Fehler für an 3/.c. Sonst müsste man etwa mudun-dur (arabisch-türkisch) annehmen.

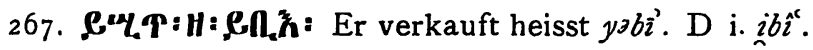
268 u.T: $\boldsymbol{H}: \mathbf{\Omega}_{\mathbf{A}} \mathbf{\hat { \mathbf { A } }}:$ Verkaufe heisst $b \vec{\imath}^{\prime}$. D. i. $b \hat{\imath}^{\mathrm{r}}$. 269 \%n: [H:] $\mathbf{0} \mathbf{Q}:$ Er hat verkauft heisst $b \bar{e}^{c} \bar{e}$. D. i. $b \hat{a} a$.

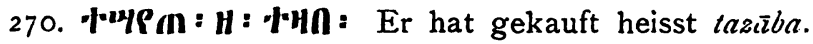
Dies ist eine ligriña-Tigrē-Glosse. 
271. Knbh:H: HAП: Trigonella foenum Graecum $L$. heisst balbā. D. i. luulba.

Statt kndh wird heute $\mathbf{h}$-n9h oder $\boldsymbol{\lambda}$-noh gesprochen.

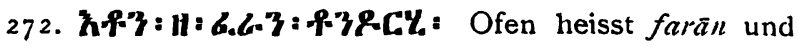
tōndōr. D, i. furn und tandīur.

In farān scheint eine Verwechslung von furn mit farrân vorzuliegen; tandîr ist natürlich dissimiliert für tannîr.

273. hT.F: : H: 6.6h: Aehre heisst farik. D. i. farik.

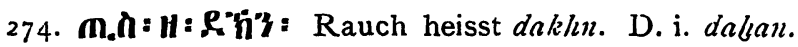

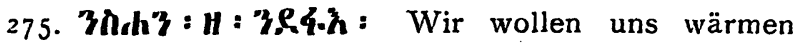
heisst $\operatorname{nad}(d) a f(f) \vec{a}$. D. i. niddaffa'.

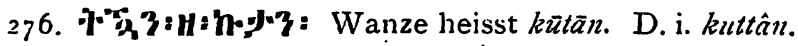

Ueber kuttân vgl. LandBerg, Etudes sur les dialectes de l'Arabie méridionale I, S. 699 und die dort zitierten Stellen.

277. $\boldsymbol{h} \boldsymbol{h}^{\circ} \boldsymbol{h}:$ : H: 9.l: : Wurm heisst dizd.

278. 7L. : : H: k-n.e: : Sklave heisst 'abd. D. i. 'abd.

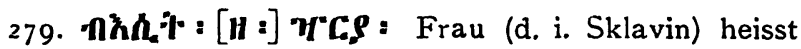
żārayā. D. i. ğâriya.

-Frau « steht hier wohl für "weiblich «, das dann auf das vorhergehende $76 S^{\circ} z$ beziehen ist.

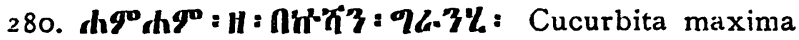
Duch. heisst bakuos̄ān und grän. D. i. wohl kîssā und gara.

Statt 96.3 ist 96.9 und $7 C 9$ zu lesen. Vielleicht ist قرع كوسا gemeint.

281. กクd: $\boldsymbol{H}: \boldsymbol{h} \boldsymbol{h} \cdot \boldsymbol{A}$ : Iss heisst 'akül. D. i. ('a)kuil.

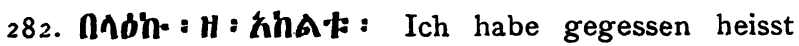
'akaltū.

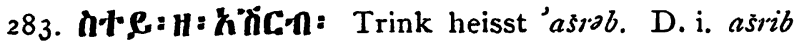
oder $a s r a b$.

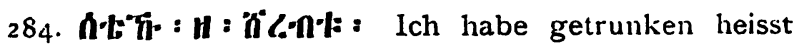
sarabtī. (D. i. saribtu?) 
285. A+ : II: Giln, Lir trank heisst saraba. (U. i. sariba?)

Statt $\boldsymbol{\Lambda} \mathcal{H}$ ist $\boldsymbol{\phi} \cdot \boldsymbol{P} \boldsymbol{\rho}$ zu lesen.

286. $1 \mathrm{A \%}:[\mathrm{H}:] \mathrm{hhn}:$ Er ass heisst 'akala.

287. A5:H:חत: Er urinierte heisst böla. D. i. bâla.

288. A3h-: 11: 1-A1: : Ich urinierte heisst bulti. D. i. bultu.

289. 3h.3: 11: 3ח-A: Wir wollen urinieren heisst nobinl. D. i. nebîl.

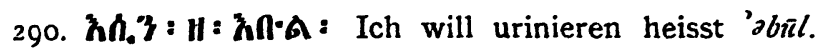
D. i. 'äbul.

291. 10नी: H: 中กA: Wasche heisst qas(s)ol. D. i. gassil.

292. "H0ח : \|l : 中n̂n: Er wusch heisst qas(s)ala. D. i. gassala.

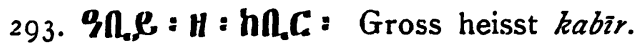

294. 9nN: H: an R.b.C: Kleid heisst madafar.

Im Tña heisst 'aläba jede Art von Kleid. Das arabische madafar wird für muaffar stehen. In dem Falle wären zwei halbe Glossen ausgefallen. Es ist mir aber wahrscheinlicher, dass das Tña-Wort hier schlecht überliefert ist; die Bedeutung ssiegreich « passt besser in den Kontext.

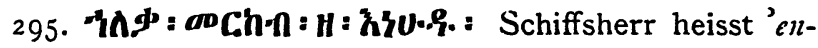
(n)ahūidū. D. i. en-nābuìda.

Das persische $n \bar{a} b \bar{u} d \bar{a}$ (von N. herangezogen) ist hier

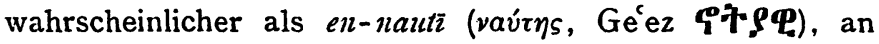
das ich gedacht hatte. Die Ausdrücke, die sich aufs Schiffswesen beziehen, stammen im Roten Meere zum grossen Teile aus dem Griechischen und dem Persischen. In diesem Falle ist das persische Wort wegen seiner Bedeutung vorzuziehen. Dazu vgl. Tē $\boldsymbol{\zeta} h \mathbf{h} \cdot \boldsymbol{g}$ »Kapitän«.

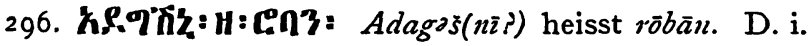
mubbân. 
Die Würde eines Adag’s(niz $)$ ist nicht genauer zu bestimmen; vgl. Perruchon, Les Chroniques de Zar'a Yấeqôb ct dc Ba'cda Mâry'âm S. 14, 101. Es muss aber ein Gouverneur zu Lande sein; daher kann rubbân hier nicht in der Bedeutung *Kapitän a genommen werden.

297. 607*:\$(B)-6.6: H:90\$\$90: General des Vortrabs heisst maqdām. D. i. muqaddam.

298. Paq3h:H:pgo3h: Deine Rechte heisst yamonka. D. i. yaminnak.

299. R390h: [H:] Gohlhh: Deine Linke heisst fiss'ärak. D. i. fî yasârak.

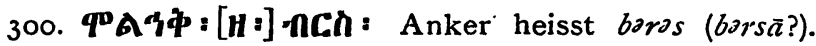
D. i. mirsā.

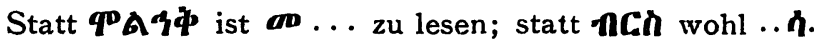

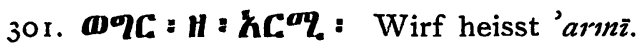

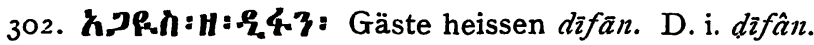

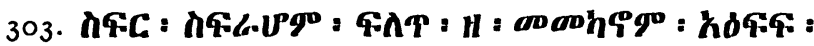
Erforsche (je?) ihren Ort heisst (ma)makānōm 'a'fof (1. a'rif).

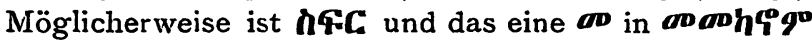
zu streichen. Doch vielleicht soll die Wiederholung der Buchstaben ein distributives Verhältnis ausdrücken; man(m)akānōm wäre dann nach Weise des Tigrē gebildet.

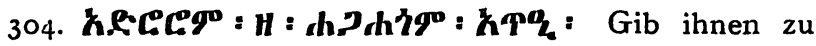
essen heisst hagāhlugōm 'ați

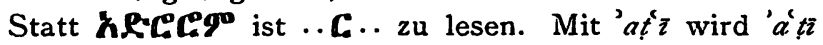

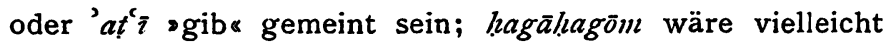
distributivisch $>$ je ihr Recht .

305. 6.\$R

306. Mh-n: H: 30.A : Lohn heisst naul.

307. hinh:[H:] K9e:Ph: Ich werde dir geben heisst 'áādajakā. D. i. 'addîka.

308. K.bunh: H: Oqh9l-Ph: Er wird dir nicht geben heisst mi'a àdoyakā. D. i. ma-íaddîka.

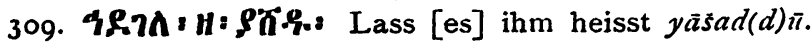
Zeitschr. f. Assyriologie, XXI. 
Statt $48.7 n$ ist ... A zu lesen. Die Uebersetzung $y^{\prime} \bar{s} \boldsymbol{s} a d(d) \pi$ kehrt wieder in No. 312 und 370; leider ist auch claraus nicht viel zu ersehen.

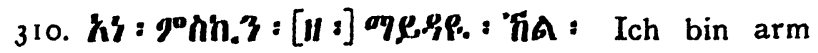
(elend) heisst mäydãyz khal.

In dem arabischen Aequivalent scheint dab̧̧îl mit irgend einem anderen Worte zusammengefallen zu sein.

311. h.Pogerq: H: aqun.: Er lässt nicht heisst méhal(l)i. D. i. ma-ỉzalliz.

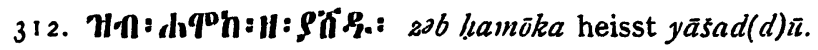

Tigriña und Arabisch sind mir hier unverständlich.

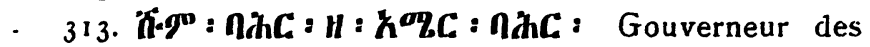
Meeres heisst 'amēr bālır. D. i. 'amîr bahır.

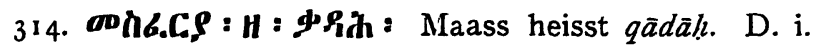
qadall.

an M6.C.P ist ein nicht sehr grosses Maass in Form eines Bechers; daher die arabische Uebersetzung.

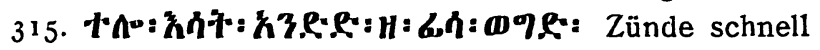
ein Feuer an heisst $f \bar{i} s(s) \bar{a}$ wag(g)ad. D. i. fissā waqqid.

Statt talō würde man heute gewöhnlich tolō '⿳亠丷冖lka sagen.

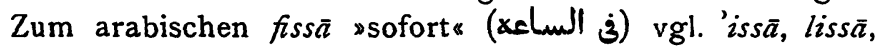
syr. $h \bar{a} \bar{s} \bar{a}$ u. s. w.

316. hn-h: H: ...hp?: Dienstag heisst ...' ayuin.

Hier ist etwas ausgefallen.

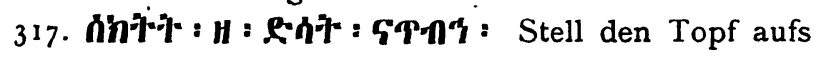
Feuer heisst dasāt nātbab. D. i. dast națbul.

Statt $\boldsymbol{\ell} \mathbf{h}$ F ist wohl $\cdot \mathbf{n} \cdot \mathbf{z u}$ lesen.

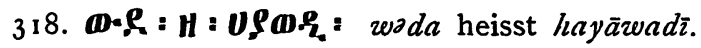

Tigriña und Arabisch sind unsicher. Am ehesten ist im Tña me (waî) 》o weh!^, im Arabischen hayā wailī zu lesen.

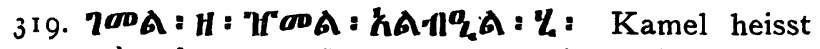
żamal und 'albs'il. D. i. ğamal und $a l-b a^{2} \hat{\imath} r$.

320. Un: H: U⿻: Gib heisst hat. D. i. hât.

Statt $\boldsymbol{U} \boldsymbol{n}$ wird hier $\boldsymbol{U} \boldsymbol{n} \mathbf{z u}$ lesen sein. 


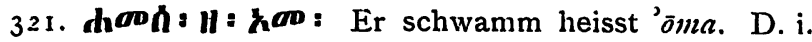
'âma.

322. 3di'n:H:3h-90: Wir wollen schwimmen heisst $n \partial^{3} \bar{u} m$. D. i. $n a^{\hat{\imath}} \hat{u} m$.

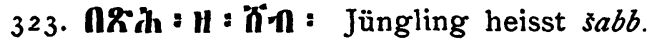

Im Tña und Tē ist ng h der erwachsene junge Mensch, arabisch بالغ.

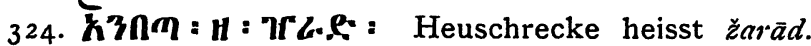
D. i. ğarâd.

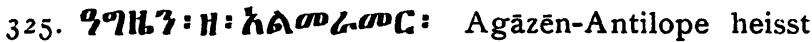
'almarāmar.

Statt 994.3 ist 0,.. zu lesen. In 'almarāmar könnte 'ärâm stecken.

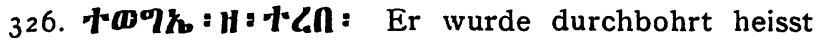
taraba. D. i. taqaba(?).

Das $r$ in taraba statt $q$ (ثقب) mag durch das folgende daraba (in 327) entstanden sein; vielleicht ist tuqiba gemeint.

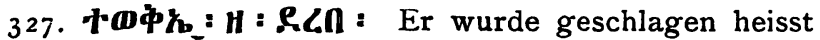
daraba. D. i. daraba (duriba?).

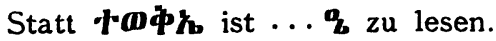

328. 8: D. i. gannat.

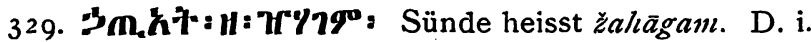
gahannam.

Das Missverständnis in 328,329 ist leicht erklärlich.

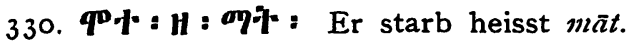

331. hed:H:గinad: Er wurde gesund heisst salama. D. i. salima.

332. A9n: R: : H: F'tfC: Reich (und freigebig) heisst tož(ż)ar. D. i. tŭğgâr.

Im Té heisst tod'är 1. Kaufmann; 2. reich; genau dasselbe bedeutet das Harari-Wort báu (aus Ge'ez ndA).

333. 3Rf: H:90nh.3: Arm heisst maskin. D. i. mäskin (oder miskin). 
334. 中h.h:7l:7h.h: Priester heisst gasis. D. i. qasis.

335. Ihhn : II: fonOD.: Sie haben sich versammelt heisst yJam(mt)ח. D. i. iltammin(?).

336. Ihn-: $\|[: \mid$ noo., Sie sammelten heisst $\operatorname{lam}(m) \pi$. D. i. lammit.

337. గ中 : II: Kत7: Er hängte auf heisst 'al(l)aga. D. i. "allaga.

Statt h中 ist . 中. zu lesen.

338. กคด:H:hАๆ: Hänge auf heisst 'al(l)'g. D. i. 'alliq.

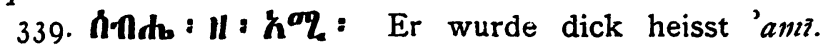
D. i. 'âma.

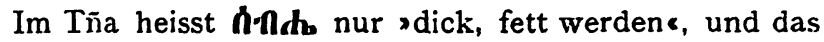
passt hier am besten in den Zusammenhang. Das arabische Aequivalent ist dadurch zustande gekommen, dass von dem Schreiber oder von dem Manne, bei dem er sich erkundigte, das $\Gamma \tilde{n} a-W o r t$ in der Bedeutung des arabischen sabaha gefasst wurde. In No. 321 und 322 ist die richtige Uebersetzung von 'âma, i. e. hammasa gegeben.

340. Uand : H [:] aDp.t:3: Er war hässlich heisst mayìtżn(?).

Möglicherweise ist mayītīn aus ma-ițî́b verdorben.

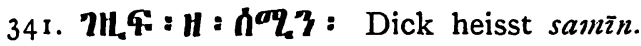

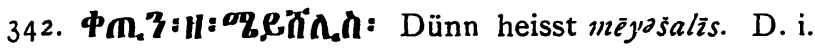
ma-isallis (?).

Das arabische Wort würde bedeuten ses hat keine tiefen Wurzeln«, etwa von einem dünnen Grase gebraucht. A ber die Deutung ist unsicher. Bezold denkt an die Wurzel جلَ. 343. FAn : H: h-nA: Tau heisst habl.

344. h-cF: 00\%k: H: hCh: Lanze heisst harbā. D. i. harba.

Das Tña-Wort $m \boldsymbol{m} \%$ ist hierhergeraten, nachdem es sein arabisches Aequivalent verloren hat.

345. Ahh: H: hel: : Er schickte heisst sad(d)ara. 
Es könnte scheinen, als ob wir hier die arabische Form des syrischen saddar hätten; es wird aber doch wohl saddara gemeint sein.

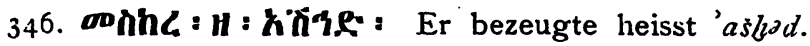
D. i. as/lid.

347. HLn : H: hihce : Pflüge heisst 'osroț. D. i. ulurut(?).

348. $+a 03: H:$ Uhe'ti : Schlange heisst hanais. D. i. l.anaš.

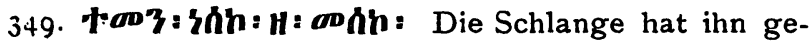
bissen heisst masakō.

Das abessinische Aequivalent steht hier in der Ge'ez-

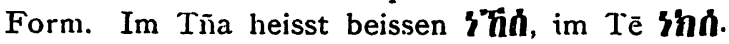

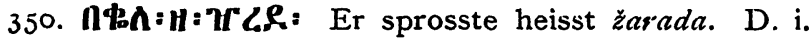
ğarida (?).

Hier sind wohl zwei halbe Glossen ausgefallen. Andernfalls hätte der Glossator gerade das Gegenteil des abessinischen Wortes gegeben.

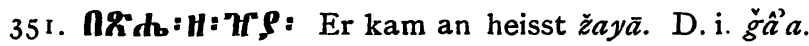

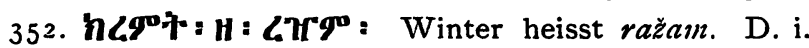
rağab(?).

Die Erklärung ist unsicher. Möglicherweise fiel der rağab gerade in den Winter, als der Glossator seine Erkundigungen einzog.

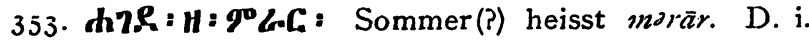
laarâr(?).

Statt h7l wird h, $\mathbf{g} \mathbf{g u}$ lesen sein, zumal es hier im Gegensatze zu hlo' $\mathbf{7}$ steht. Das arabische harâr ist nur erraten; man würde auch eher harr oder harârat erwarten.

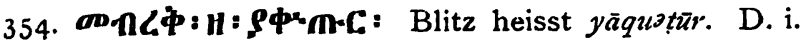
yaqtur (es träufelt?).

3.55. 370R:H: P中'CA: Donner heisst yäquarat. D. i. yaqrut (es kracht). 


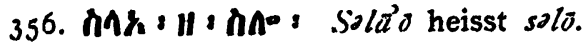

Solito heisst heute $\operatorname{sel}(12)^{\prime} \partial$; daher ist $n \cap P$ zu schreiben. 357. X390:\|: hn: Enquáa heisst kêla. D. i. kêl(a). Ein 'ongat $a$ Korn entspricht etwa I Kilogramm; sal'o ist kleiner als 'ongá $\bar{a}$.

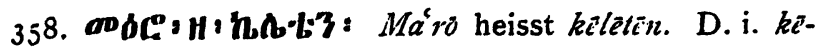
latên.

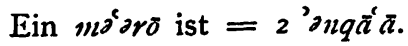

359. 3F:中 : H: 3h-h : Nofoq heisst nòns. D. i. nuṣs. Ein $n \supset f o q$ ist $=8$ 'snqấa $\bar{a}$.

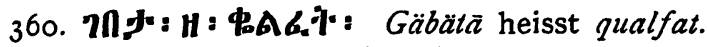

Ein gäbätā ist $=18$ (?) 'snqā $\bar{a}$.

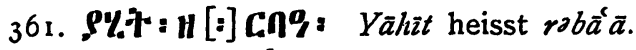

Ein $y \bar{a} h \bar{z} t$ (1. $\left.\boldsymbol{S}_{\boldsymbol{h}} \mathbf{T} \mathbf{)}\right)$ ist $=4$ gäbätā.

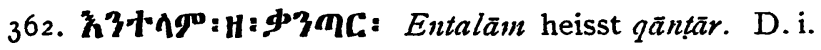
quntâr.

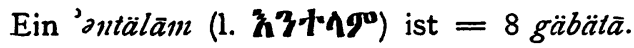

Ueber diese Tigriña-Maasse vgl. Contr Rossını, I Loggo e la legge dei Loggo Sarda, Firenze, 1904, pp. $14 \mathrm{ff}$.

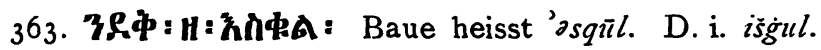

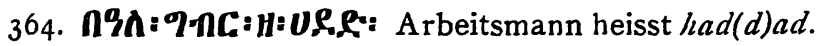
D. i. lıaddâd.

365. O742:90H:KA4.Un: Axt heisst alfähas. D. i. al-fâs.

Statt 092 ist 99 \%\% zu lesen. Dies Ge'ez-Wort wird. heute im Tña nicht mehr gebraucht. Das $\mathcal{g}^{0}$ vor $\boldsymbol{H}$ ist $z \mathbf{u}$ streichen.

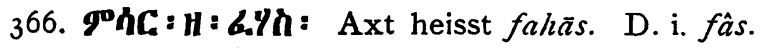

gohc ist das moderne Wort für Axt, Hacke.

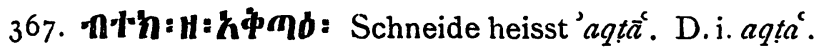

368. RL Ln : H: antice: : Zimmere heisst ..... masar(r)od. fallen.

Hier sind wahrscheinlich zwei halbe Glossen ausge- 


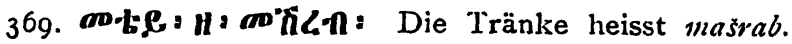
Statt mite wird andt zu lesen sein.

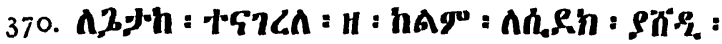

Sprich zu deinem Herrn heisst kal(l)am lasĩdak y'üsad(d)ì. D. i. kallin sî̀lak .....

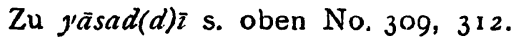

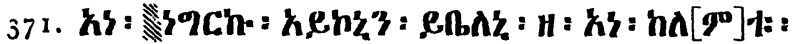
$09.34 ., 37$ : Ich habe gesprochen; er sagte zu mir "Es

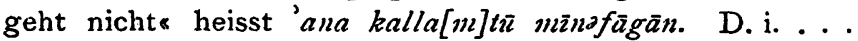
$m \bar{a}$ nafá $n \bar{i}(?)$.

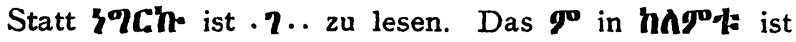
im MS. ausgefallen. Statt $02,34 ., 73$ wäre etwa $0744 . \% \%$ zu lesen.

372. $\mathbf{B h}-\mathbf{7}:$ :1:00nah: Es geschehe heisst malth.

373. hnRAด : II : hne:C: Ich schicke dir heisst 'asad(d)ar.

Zu sad(d)ara vgl. oben No. 345 .

374. nRe::[n:] he:c: Schicke heisst sad(d)ar. D. i. șaddir.

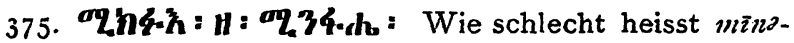
fähè. D. i. ma-yinfá (?).

376. U'h:H:Uh: Nimm heisst hak. D. i. hâk(?).

Etwa $l+$ Suffix in der Bedeutung sda bist du, da hast due. Vgl. das jerusalemische hai mit Suffix, das damascenische lêkō.

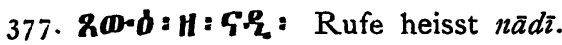

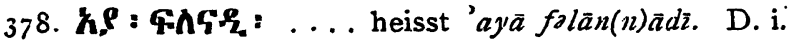

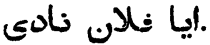

Hier ist wohl das Tigriña-Aequivalent ausgefallen; sonst wäre diese Glosse ein Zusatz zu dem arabischen Teile von No. 377.

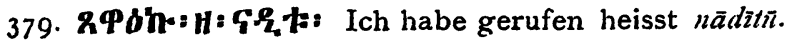
D. i. nādêtu. 
380. '7c:h. : II : hnF'h-: Ich habe gesprochen heisst kal(l)amkn. D. i. knallamtu.

381. unapdi:H:00Cdh'm73\%, Mühle heisst marllake und tahän.

Beide arabischen Worte scheinen schlecht überliefert zu sein. In marlaka steckt wohl rahia und eine Ableitung von llaraka; statt tahän ist am besten täliuin zu lesen. Bezolv denkt an eine Verwechslung von sMühles und Müller (ḷalılıān).

382. m/3:H:ha43 : Mahle heisst 'atbon. D. i. ațin oder athan.

Statt my? ist $\cdot \boldsymbol{h} \cdot z \mathbf{u}$ lesen.

383. Mh3: H: R.中中: Er mahlte heisst daq(q)aqa.

Statt $\mathbf{m d} \mathbf{3}$ ist .. $\mathrm{zu}$ lesen.

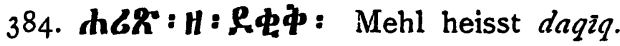

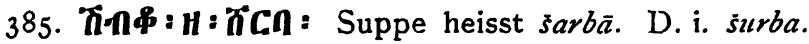

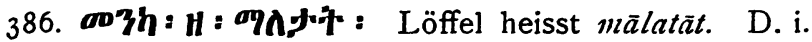
má laqat.

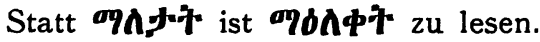

387. F.C.: H: $\boldsymbol{h} \mathbf{\phi}:$ Urteil heisst haqq.

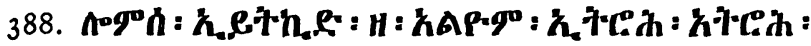

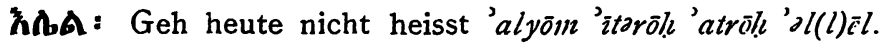
L. al-yôm lâ tevîlh, terîh el-lêl.

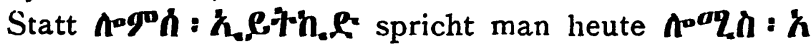
etonge.

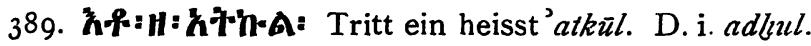
Vgl. hierzu oben No. 192.

390. R.C:H: Ż.A: Trage heisst sīl.

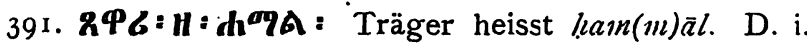
lıannmâl.

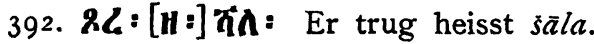

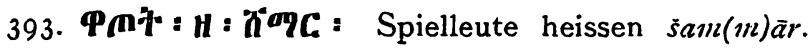
D. i. summār.

Die Erklärung sumımār stammt von $\mathrm{N}$. 


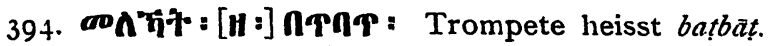

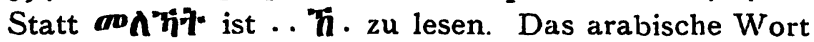
ist mir in dieser Bedeutung nicht bekannt.

395. hIC: H: Rnth: Pauke heisst $\operatorname{dalok}(k) a$. D. i. darābukka.

396. KnC:H:KCAT: Binde heisst 'arbutt. D. i. arbut.

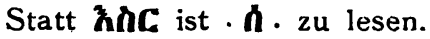

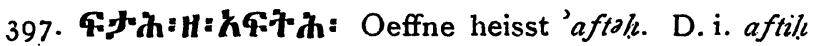
oder aftalu.

398. Ћ3П: H: TrПA : Bergkuppe heisst žabal. D. i. ğabal.

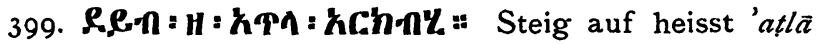
und arkab. D. i. atla' und arkib (oder arkab).

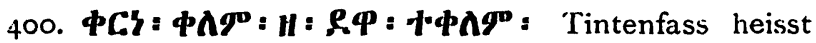
darwā taqalan. D. i. dazūt(a) qalam.

Vielleicht wurde in Massaua teilweise auch im Arabischen qalam in der Bedeutung "Tinte" gebraucht wie im Abessinischen.

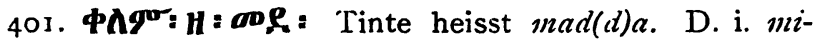
dâd oder mudda.

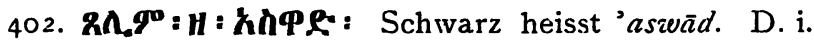
'aswad.

403. PRo : H: h90 L: Rot heisst liamrā.

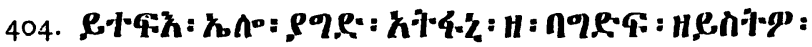

Hier fehlen die arabischen A equivalente.

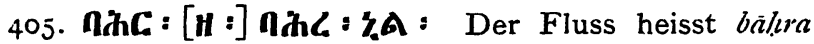
$n \bar{\imath} l$. D. i. balı̀r an-nîl.

406. h\%नी:H: 中nA: Wasche heisst qassal. D. i. gassil.

407. hRी.:[H:] \$กA: Wäscher heisst qassäl. D. i. gassâl.

Statt \$nA ist . h. zu lesen.

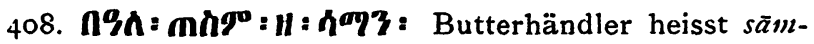
(m) ān. D. i. sammân.

Statt h093 ist $\boldsymbol{n} . \mathrm{zu}$ lesen. 


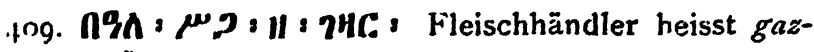
(i)ar. D. i. 乌̆azzâr.

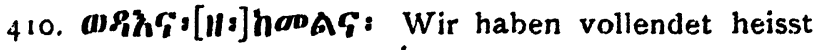
kam(m)alnä.

411. hq: : H: horh.: Mund heisst ..... kamst.

Die Glosse steht am unrechten Ort und ist kaum richtig überliefert. Ursprünglich hat der Verfasser wohl mit No. 4 ro abgreschlossen. Man könnte hF zu hG: swie"

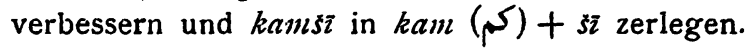

II. Amharisch - Arabisch (Aegyptisch).

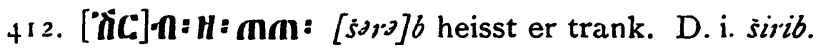

Der Anfang dieser Glossen fehlt; die beiden Buchstaben sind von mir ergänzt.

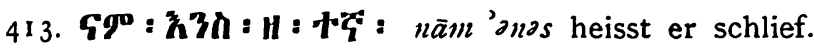
D. i. $n a \hat{m}=$ en-nâs(?).

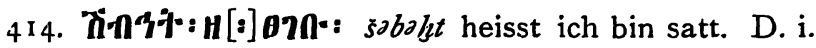
sibillt.

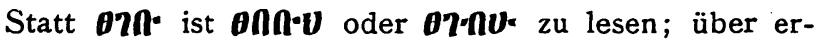
stere Form vgl. Praetorius, Amhar. Sprache $\S 64 \mathrm{~b}$.

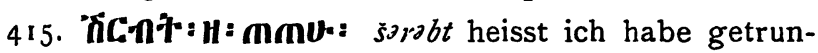
ken. D. i. širibt.

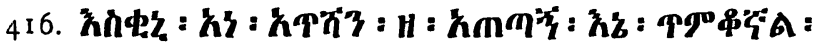
'asqīnī 'ana 'ațsān heisst gib mir zu trinken, ich bin durstig. D. i. isqînī 'ana 'ațî̀n.

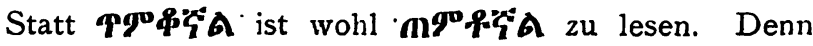
an mad中 "auspressen " ist hier kaum zu denken.

417. $\$ 904: H: \lambda 3 \ell_{0}[:]$ qaml heisst Weizen. D. i. qaml.

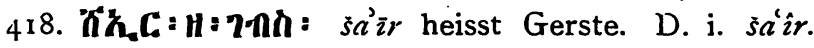

4I9. 4.ム: H: П\$A: fïl heisst Bohne (Vicia Faba L.). D. i. fî̀l. 


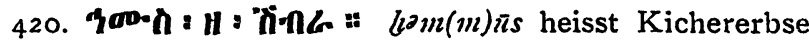
(Cicer arietinum L.). D. i. hutmmus.

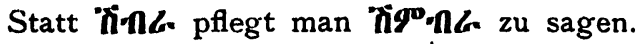

$42 \mathrm{I}$. 99 : H: D.U : mãya heisst Wasser. D. i. mâya (oder moiya).

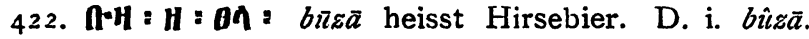
nabid.

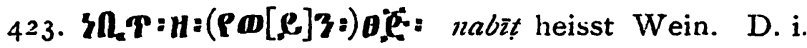

Die Buchstaben $\mathbf{P W}^{3}$ sind von zweiter Hand hinzugefügt.

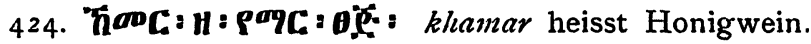
D. i. bamr (oder bamar?).

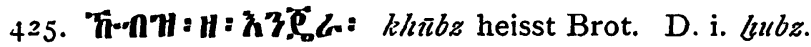

426. $\mathbf{m \Omega} \mathbf{U}: \mathbf{H}: \mathbf{m 8}:$ tabih heisst gekochtes Essen. D. i. tabizb.

Statt $\mathbf{m} \mathbf{R}$ ist $\boldsymbol{\Phi g}$ zu lesen; vgl. GuidI, s. v. (MT. Vgl. No. 533 .

427. б: He:hn: $f \hat{i}$ heisst es gibt. D. i. $f \hat{i}$ (oder $f \hat{\imath} h$ ). He ist zu $\mathbf{H} \mathbf{E}$ zu ergänzen.

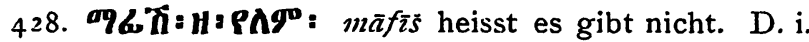
$m \hat{a}$ fîs.

429. Khe: H: mhe: 'akhad heisst er nahm. D. i. 'aluad.

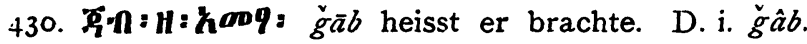

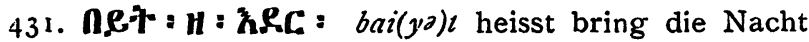
zu. D. i. baiyit (oder bît).

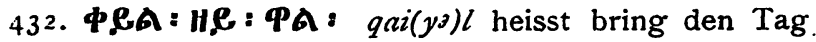
(Mittagszeit) zu. D. i. qaijil (oder qîl).

Ueber die Bedeutung von Pत vgl. Guidi, s. v.

433. HZ:H:KAn: zan(n) heisst er dachte. D. i. żann.

434. hOOA:[H:] hel.7: 'anal heisst er machte. D. i. 'antal.

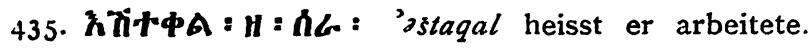
D. i. istagal. 


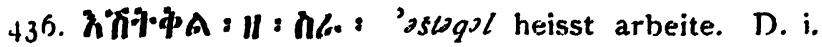
isligil.

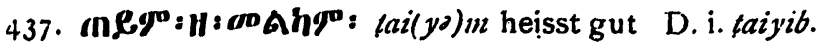
hadd.

438. h.:: H: औb.Lh: l.ad(d) heisst er zerstörte. D. i.

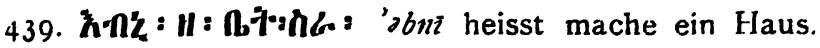
D. i. $i b n z$.

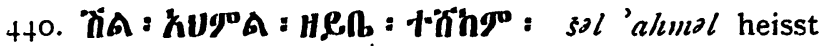
nimm auf die Schultern. D. i. sîl alımil.

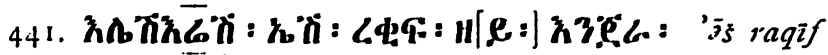
heisst Brot. D. $\overline{\mathrm{i}}$. ' $\hat{e} \bar{s}$ ragîf.

Das erste Wort ist verschrieben und sollte wohl ganz getilgt werden, wie die Striche anzeigen.

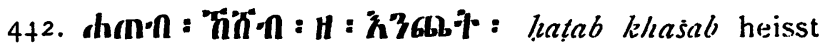
Holz. D. i. llatab und basab.

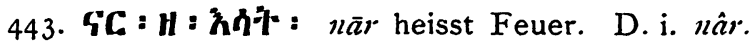

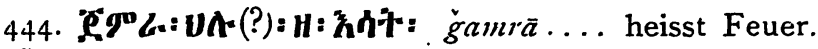
D. i. gamra.

Hier scheint ein amharisches Wort $\boldsymbol{v} \boldsymbol{\Lambda}=\boldsymbol{\hbar} \boldsymbol{h} \boldsymbol{F}^{\mathrm{zu}}$ sein; vgl. No. 554 .

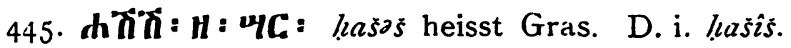

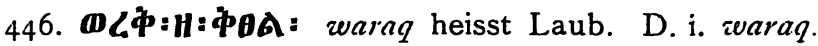

447. A,C: : Н: нक्: : săgar heisst Baum. D. i. săgar (oder šăgar).

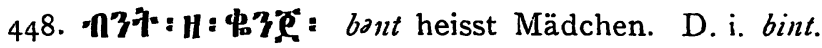

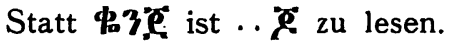

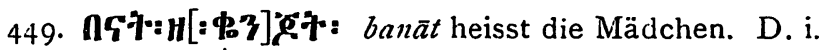
banât.

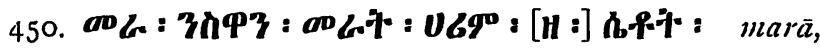
noswān, marāt, harīm heisst Frauen. D. i. mara, niszuân, marat, harin.

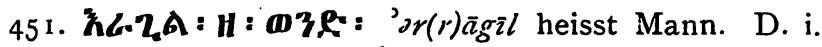
er-râgil. 


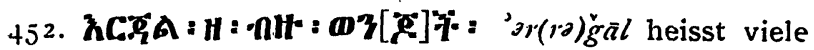
Männer. D. i. èr-rìgầl.

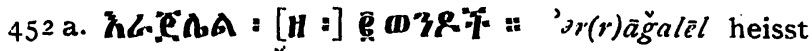
2 Männer. D. i. cr-răğilên.

453. Dne: H: A $\mathbf{E}:$ : walad heisst Kind. D. i. rvalad. 'iztigâr.

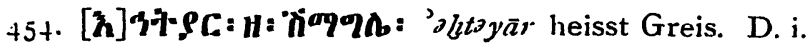

Das erste Wort ist im MS. sehr undeutlich.

455. \$h.h : H: $\mathbf{\phi} \boldsymbol{h}$ : qasis heisst Priester. D. i. qasis.

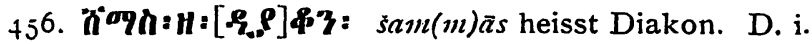
sammmâs.

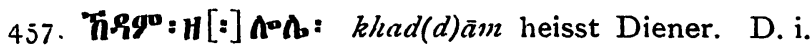
baddâm.

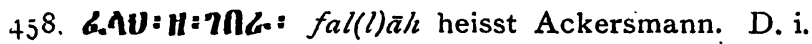
fallâlı.

Statt $7 \mathrm{n} 6$ ist $7 \mathrm{n} 6 \mathrm{zu}$ lesen.

459. 3U-ก: H [:] \$ ...: nahab heisst er hat geraubt. D. i. nahab.

Da drei Buchstaben ausgefallen zu sein scheinen, wird man wohl die Form $\mathbf{\phi [ \boldsymbol { g } ^ { \circ } \mathbf { A }}$ ] zu schreiben haben. Ueber diese ältere Gerundivbildung vergl. Praetoriur, Amhar.

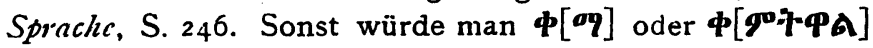
lesen.

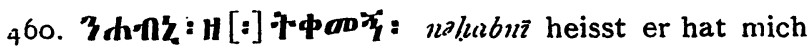
beraubt. D. i. nahabni.

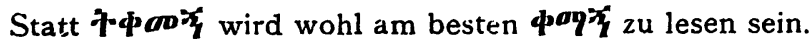

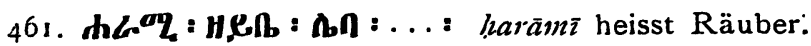
D. i harâmĩ.

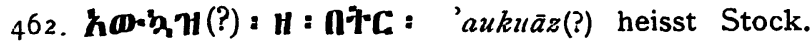
D. i. 'ukkâa.

Die Erklärung ' $u k k \hat{a} z$ stammt von $\mathrm{N}$.

463. 4.7:H[:] hत6.: fät heisst er ging vorbei. D. i. fât. $46+.4 \cdot 7 \cdot \mathbf{H}: \boldsymbol{\lambda}[\boldsymbol{\Lambda} F]$ : füt heisst geh vorbei. D. i. fît. 


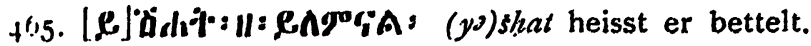
D. i. jistlat.

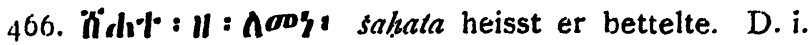
sallat(a).

Statt 7 hम ist vielleicht .. ๆ zu lesen.

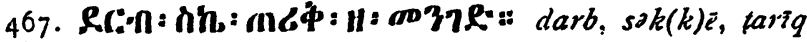
heisst Weg. D. i. darb, sikke, tariq.

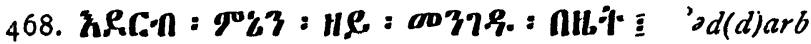
man'n heisst wo (wie) ist der Weg. D. i. cd-darb minên.

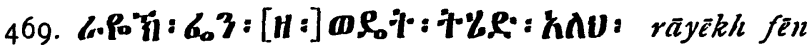
heisst wohin gehst du. D. i. râyił̆ fên.

hnv ist von zweiter Hand hinzugefügt.

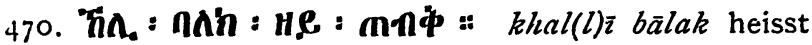
warte. D. i. לallī bâlak.

47 I. L.bP: : H : (H :) $\mathbf{m} \boldsymbol{中}$ : $\quad r \bar{a} \partial y \bar{z}$ heisst Wächter. D. i. $r a \hat{z} \bar{z}$.

472. ก中lo:H: 100: baqarā heisst Kuh. D. i. baqara.

473. PC: : H: त6 : tör heisst Stier. D. i. tôr.

Nach Guidr, Voc., col. 327 ist M6 die gewöhnlichere Form. - 6 , das daneben vorkommt, entspricht genauer dem äthiop. nbl.el.

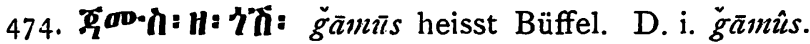

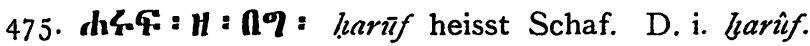

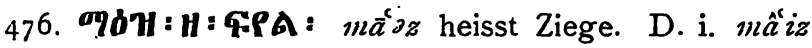
oder $m a^{\prime} z$.

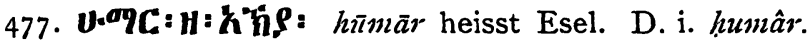

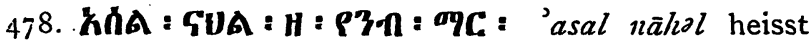
Bienenhonig. D. i. 'asal nalıl.

PYन ist von zweiter Hand hinzugefügt.

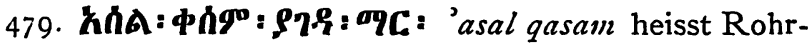
zucker (eigentl. Rohrhonig). D. i. 'asal qașab.

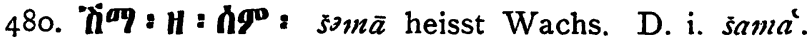
481. An3: H: Drep: laban heisst Milch. D. i. laban. 
482. A903: H: \$廿 saman heisst Butter. D. i. samun.

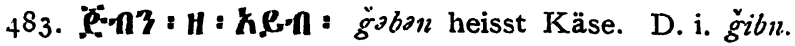

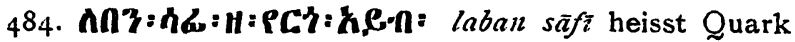
(durchgegebene dicke Milch, vgl. Guid, col. 13t). D. i. laban șấfī.

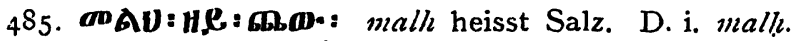

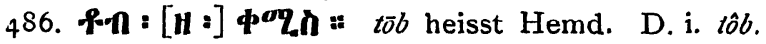

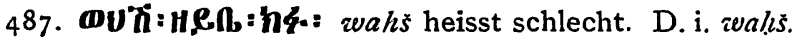
'a'wag.

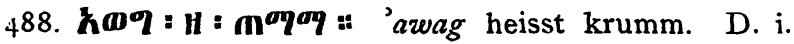

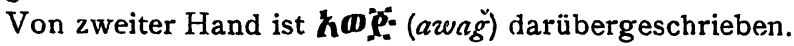

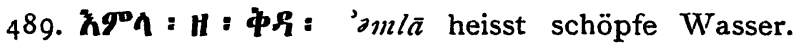
D. i. inla.

Von zweiter Hand ist 6.C\$ ( faraq) darübergeschrieben. Das beruht wohl auf einer Verwechslung von خرف und

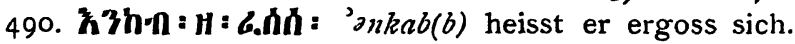
D. i. inkabb.

491. 6.\$耳:H:h6.W: fatāh heisst er öffnete. D. i. fatal. 492. \$לु.A:H:H.?: qafal heisst er schloss. D. i. qafal.

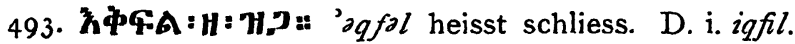

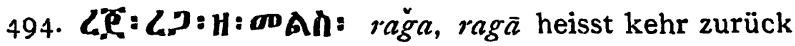
(1. er kehrte zurück?). D. i. rağá ragá.

Wenn man rağa und raga nicht als Perfecta lesen will, so müsste man sie zu irğa und irga verbessern; das würde der amharischen Uebersetzung besser entsprechen.

495. \$Lनी: H: \$Lनी: qarab heisst komm heran. D. i. iqrab(?).

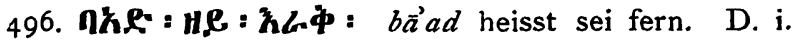
$i b^{\mathrm{k}} a d(?)$.

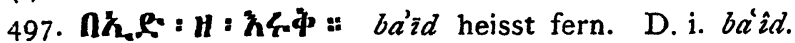

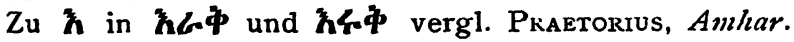
Sprache, \$67b.

498. \$C\&=ी: [H:] \$C:-n : qaraib heisst nahe (nahe Verwandte?). D. i. qarîb (qarâyib?). 
Wahrscheinlich ist die Form qarâyib gemeint. Dann wäre hinter \$C: $n$ im Amharischen am besten noch Horl: $z u$ ergänzen.

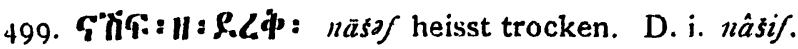

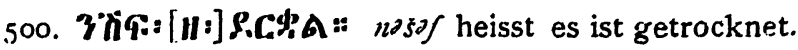
D. i. nisif.

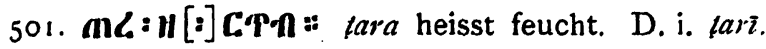

Statt $\mathbf{m} \zeta$ ist . $\boldsymbol{C}$ zu lesen.

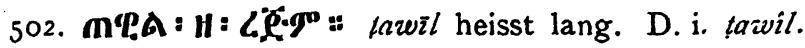

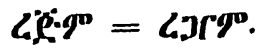

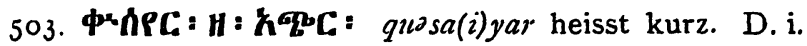
qușaiyar.

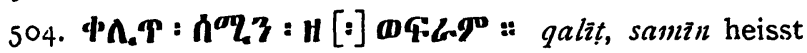
dick. D. i. galíd, samîn.

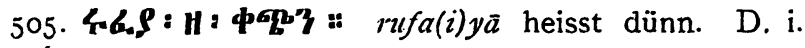
mefaiya'.

506. 4. R: H: गCC : $f \bar{a} d(d) \bar{a}$ heisst Silber. D. i. fadda.

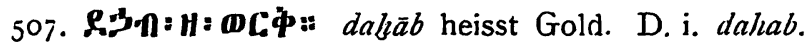
508. 3Uh:H: HCF: nahas heisst Eisen. D. i. naliâs. Hier mögen zwei halbe Glossen ausgefallen sein; etwa in : ahol: : 1 :

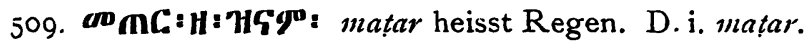

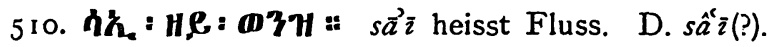

Die Lesung. hK. ist nicht ganz sicher; vielleicht ist K\%. beabsichtigt. Die Bedeutung ist auffällig. N. denkt eventuell an satt.

511. hCS: H:g0e:C: 'ard heisst Erde. D. i. ard.

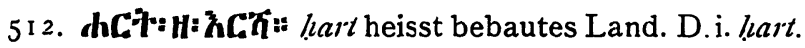

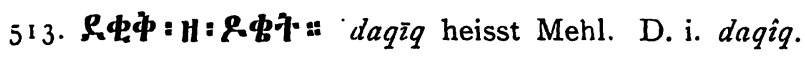

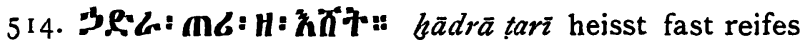
Korn. D. i. Gudra(?) tari.

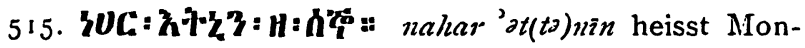
tag. D. i. nalıâr et-tenên. 


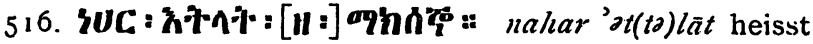
Dienstag. D. i. nahâr et-talât.

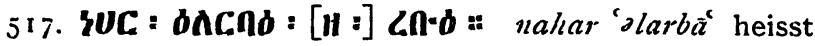
Mittwoch. D. i. nahâr el-arbai.

518. HUC: Donnerstag. D. i. naliâr el-bamîs.

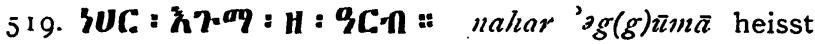
Freitag. D. i. nahâr eg-gứca.

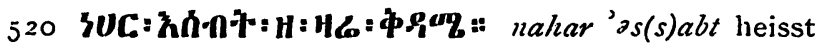
Samstag. D. i. nahâr es-sabt.

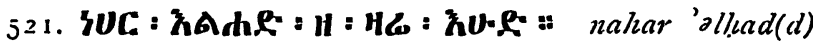
heisst Sonntag. D. i. nahâr el-liadd.

In 520 und 521 hat das Amharische vor den Tagesnamen noch wheute

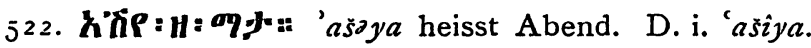

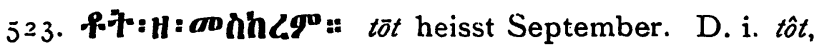
ewort.

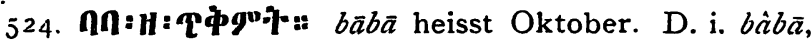
nawry.

525. UHC: H: 19C: : hatīr heisst November. D. i. latiur, dowp.

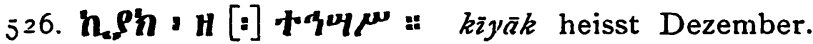
D. i. kìyâhlak, Xorak.

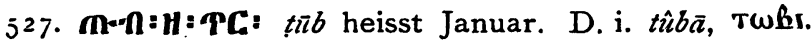

Nach dieser Glosse ist eine Lücke. Februar ist hier ausgefallen.

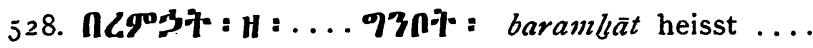

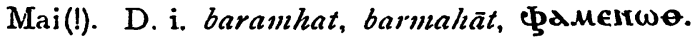

Hier fehlen zwischen barmahāt und Mai eine ganze und zwei halbe Glossen. nawits.

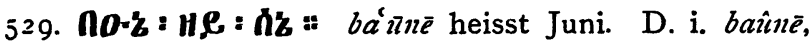
ยกIळ.

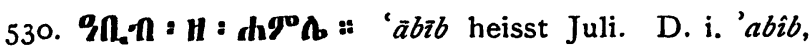

Zeitschr, f. Assyriologie. XXI. 
E. Lillmann

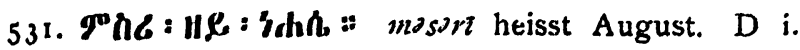
mesur, Mecorpн.

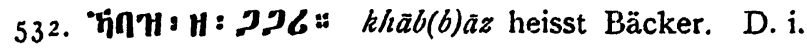
luab่âz.

533. anח. D. i. tabill.

Vgl. oben No. 426.

534. nUeq: H:ћ3hh: bahaim heisst Tiere. D. i. bahâjim.

535. T:LU:H:\&-6C:'7: forāh heisst Hühner. D. i. firâlb.

Ueber die Form P:l.CF sagt Guid, col. 654: il pl. tigrin. elaci è usato talvolta, sebbene incorrettamente, in amarico. \& Die hier gegebene Form mit \& im Anlaute ist kein Schreibfehler, sondern wegen des A nlauts im Sing. (P.C) die näher liegende Aussprache. Diese Pluralform ist interessant, insofern sie zu einer sonst im Amharischen und in Tña wenig vertretenen Klasse gehört; vgl. PRAEToRius, Tüa-Grammn., § 135. Nan bildet heute im Tña därähü (im Tigrē dawarrih). Die Form P.l.C.7 ist doch eher dem Amharischen als dem Tña zuzusprechen, da in ihr das $h$ fehlt, wie im Sing. \&C. Wäre es eine eigentliche Tña-Form, so müsste sie R.b.CUt: (oder .... F) lauten,

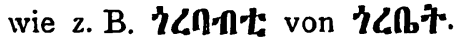

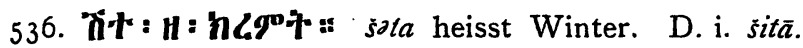

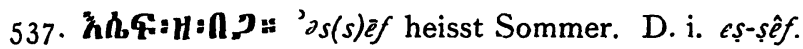
Ueber ח? vgl. Guidr, col. 349 .

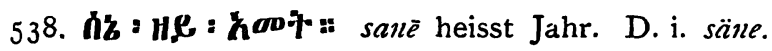

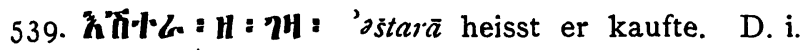
istarā.

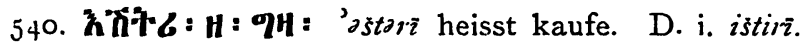

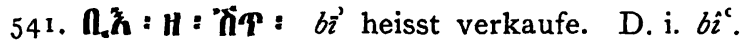

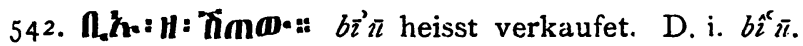

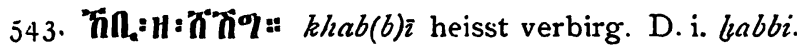

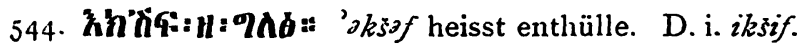


545. RAA : H [:] PC:P: a dal(l)ol heisst bedecke (beschütze). D. i. dallil.

Das amharische $36 \%$ hat eine Reihe von verschiedenen Bedeutungen; vgl. Gordr, s. v. Hier muss es wegen des arabischen Aequivalentes so übersetzt werden, wie oben angegeben ist.

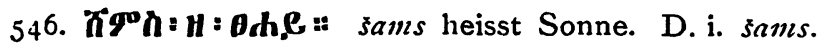

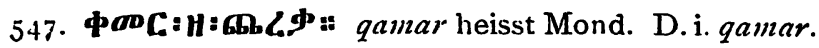

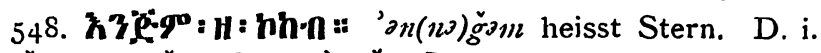
(n-nă̆m (en-niğm) [oder 'anğum].

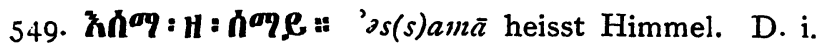
es-samā.

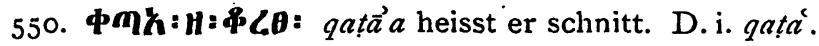

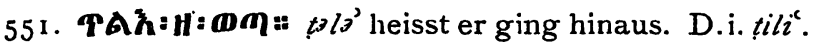

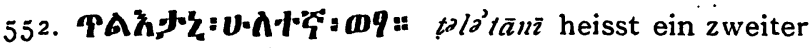
ging hinaus. D. i. tillítânī oder $\epsilon t-t a ̂ n \bar{t}$.

553. CC: H: $\hbar \lambda$ F : $n \bar{a} r$ heisst Feuer. D. i. nôr.

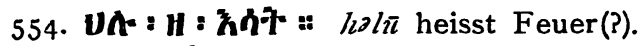

Zu vit: vgl. No. 444 .

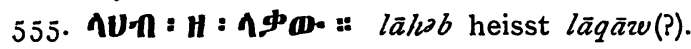

Das arabische Wort ist wohl lahab »Glut«. Dem würde im Amharischen lābät oder lābōt entsprechen.

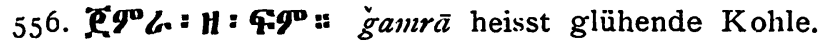
D. i. gamra.

557. AP3: [H:] TP:a qntan heisst Baumwolle. D. i. quț.

558. Фนด : H[:] 6.7-A: qazl heisst Faden. D. i. gazl: qaía.

559. \$C9: H: \$A: qar $a$ heisst wilder Kürbis. D. i.

QA scheint nach Guidi's Angaben s. v. Cucurbita maxima Duch. zu sein; vgl. oben No. 280.

560. Thit: H: Mh: tost heisst tâs. D. i. tist (Becken).

Das amharische Wort $\boldsymbol{\eta n}$ ist arabisches Fremdwort. Im Tña bedeutet tâa $\bar{a}$ eine grosse irdene Schale. 
56r. "hinn:[11:]hon:: khas(s)ala heisst er wusch. D. i. bassal(a).

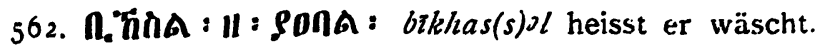
D. i. bilbassil.

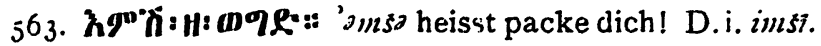

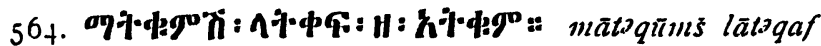
heisst steh nicht auf. D. i. mâ tcquimss, lâ tiqaf.

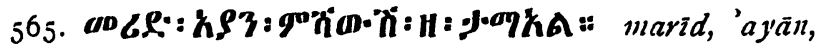
mośãzojs heisst er ist krank. D. i. marîd, 'aiyân, musauzwas.

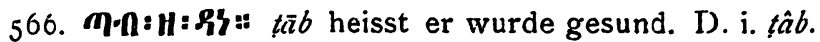

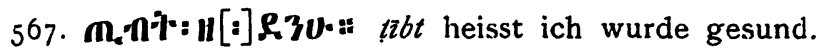
D. i. tibt.

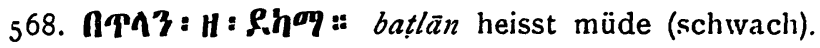
D. i. batlân.

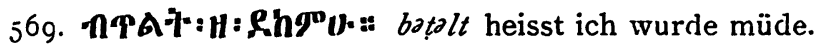
D. i. bitilt.

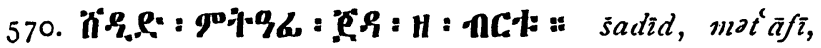
ğadā heisst stark. D. i. sadîd, mut $\hat{a} f \hat{z}, \grave{g} a d a ́$.

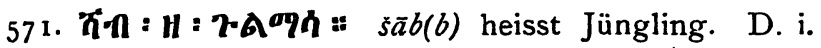
$\check{s} \hat{a} b b(\check{s a ̈ b b)}$.

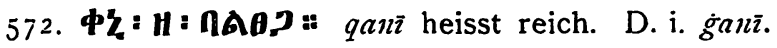

573. 6.中С: : Н [:] e.3 : faqir heisst arm. D. i. faqir.

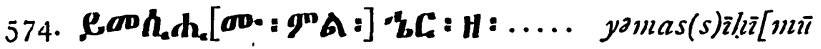
mol] hèr heisst ..... D. i. imassîkum bil-bêr.

Das amharische Aequivalent fehlt. Die eingeklammerten Worte sind sec. manu hinzugefügt.

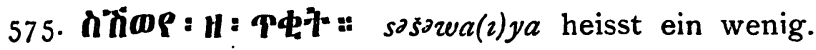
D. i. suzwaiya.

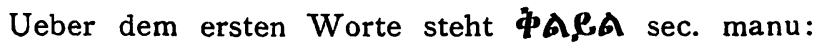
qalayal. D. i. qalîl.

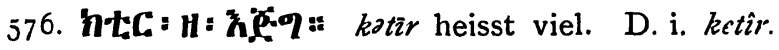

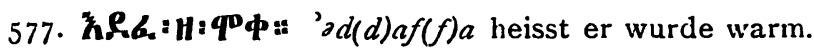
D. i. idldaffā. 
578. hF: H: hP : $s \bar{a} f$ heisst er sah. D. i. šâf.

Statt hF: ist $\mathbf{K F} z \mathbf{z}$ lesen.

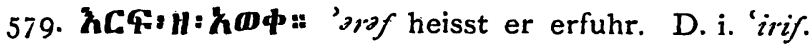

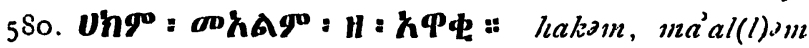
heisst klug. D. i. lıakîn, miallim.

III.

Ge'ez - Amharisch.

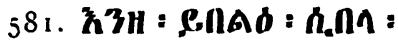

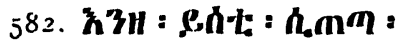

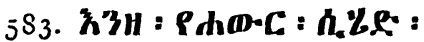

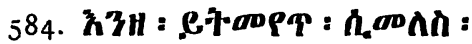

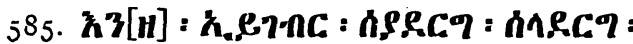

In der Kopie steht statt des $\boldsymbol{H}$ ein $\boldsymbol{\Lambda}$ mit einem Fragezeichen.

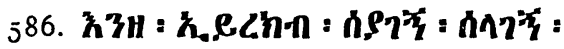

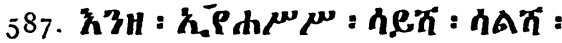

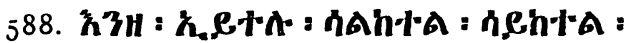

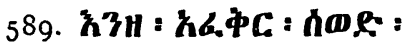

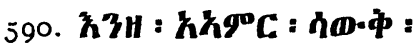

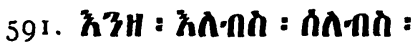

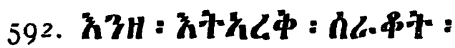

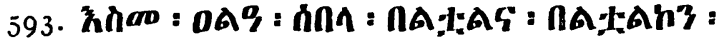

Statt $0 \triangle 9$ ist $\mathbf{n} \ldots$ zu lesen.

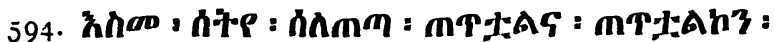

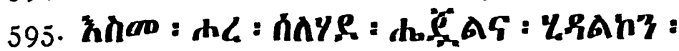

Im dritten Worte ist $\boldsymbol{\psi}$ statt $\boldsymbol{\eta}$ zu lesen; im fünften f. statt $R$.

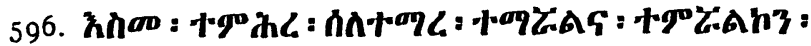

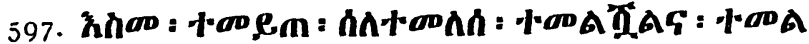
Tan'?: 


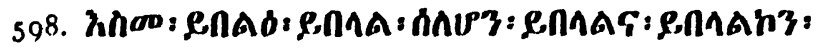
man's,

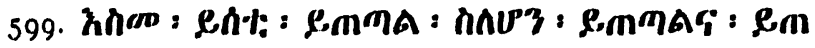

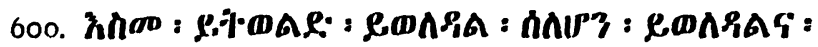
eonsab's:

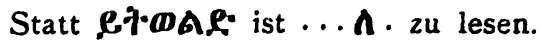

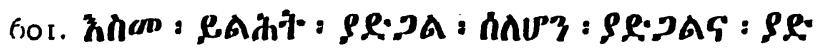
PAn?:

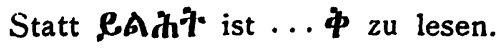

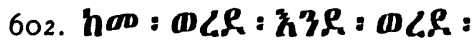

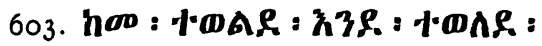

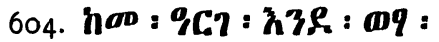

605. hav: $2000: h 3 R: 200:$

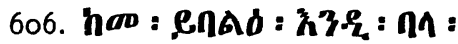

Im zweiten und vierten Worte wird $\mathbf{n}$ statt $\mathbf{n}$ zu lesen sein.

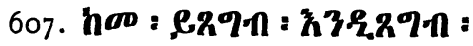

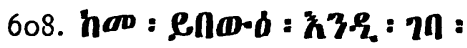

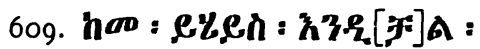

In der Kopie steht statt 7 ein Zeichen, das so sonst nicht vorkommt, das aber einem fic nicht ganz unähnlich ist.

610. has : lonnd : enN : H3e: :

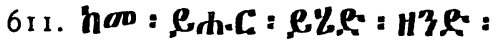

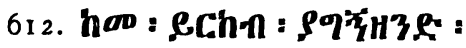

613. hav : eash : enth3e:

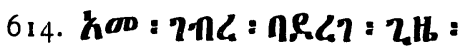

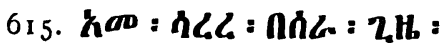

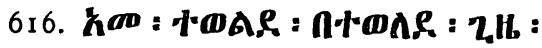

617. ha0 : 200 : $\mathbf{2 9 0 0}: \mathbf{2 H}$ :

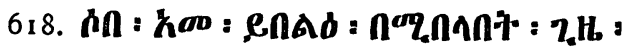

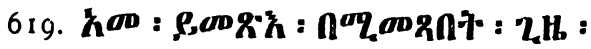




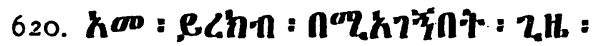

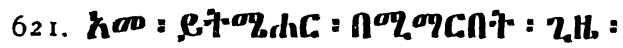

622. hinh : ПA9: hlln : l:Lh : (sic)

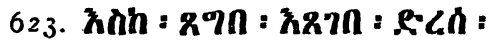

624: hih : Lap : hLh : e:ch :

Statt hLh 1. \...(?).

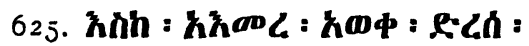

626. hith : enad : RnA : e:Lh :

Statt $\operatorname{enn}$ ist $\operatorname{enn} z u$ lesen.

627. hith : earg\% : eong : e:ch :

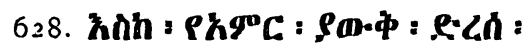

629. hin : e-nba : eh-nc: e.ch :

In 622-625 wird statt $\ell: \angle \boldsymbol{h}$ überall $\ell: \angle \hat{n}$ zu lesen sein.

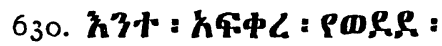

631. Ћ3+: :

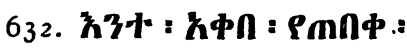

633. Ћ3F: 9C.7: PO9:

634. ћ3t : enad: paqna:

635. ᄎ3+ : ent: paqmm :

636. h3t: : PhD.c: : pqqhe: :

637. h3t : bloth : gaq.6.c.e. :

L. $\boldsymbol{e}$. $\mathbf{T} \boldsymbol{h}: \boldsymbol{P} \ldots$.

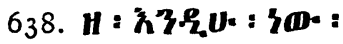

639. hn: ПAO: : PAN :

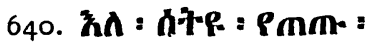

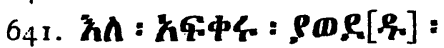

Das [. .9$]$ ist in der Kopie ganz undeutlich.

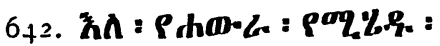

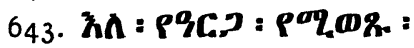

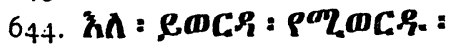

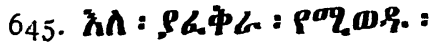

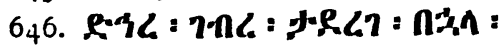




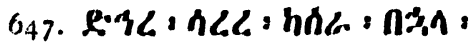

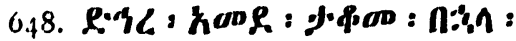

649. P:Hl: : nag a han : n:31:

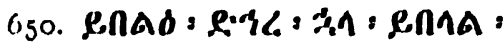

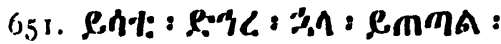

Statt $\boldsymbol{\ell} \boldsymbol{n}$ I: ist $\cdot \boldsymbol{\Lambda} \cdot \mathbf{z u}$ lesen.

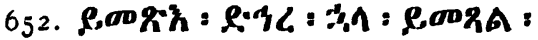

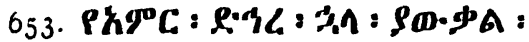

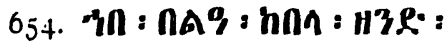

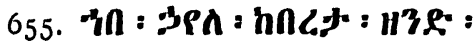

656. HI : amb : hor : H3P:

Statt h,r L ist hirom zu lesen.

657. HI : a.e.h : h6.200 : Hze: :

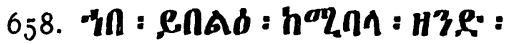

Im dritten Worte 1 . \ statt $\mathbf{n}$.

659. - HI : ent: : haqmm : H3e: :

Im zweiten Worte 1. h statt h.

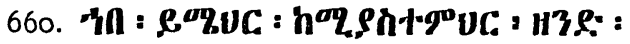

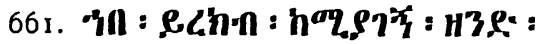

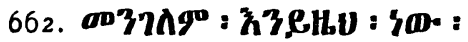

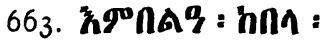

664. h90h+P : hmm :

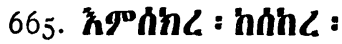

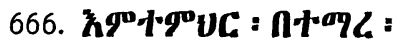

Statt $\mathbf{C}$ im ersten Worte ist $\boldsymbol{C} \mathrm{zu}$ lesen.

667. Ћ90H3a0: ПHhaD:

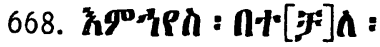

Statt h im ersten Worte ist $\mathbf{h}$ zu lesen. Ueber $\boldsymbol{y}$ vgl. No. 609 .

669. h90ennd : h.lln :

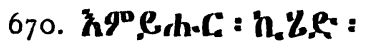




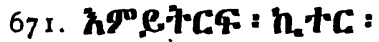

Statt $\mathbf{h} . \mathbf{H} \mathbf{C}$ ist $\mathbf{h} . \mathbf{P} \mathbf{c} z \mathrm{zu}$ lesen.

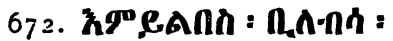

Statt ח.n-nh ist ... $\boldsymbol{n} z \mathbf{u}$ lesen.

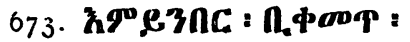

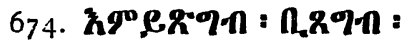

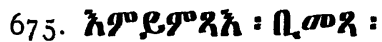

676. $\$ 9^{\circ} \boldsymbol{h}_{\text {. Lhn }}$ : hnt:

Statt ist $z$ zu lesen.

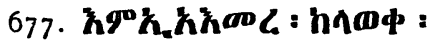

Statt $\boldsymbol{h}$ ist $\boldsymbol{h}$ zu lesen.

678. hơ

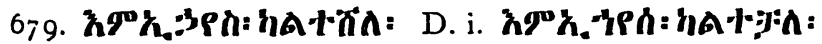

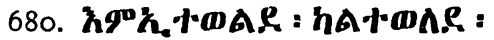

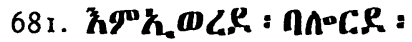

Statt des zweiten Wortes ist nAmLS oder nn-LS. $z u$ lesen.

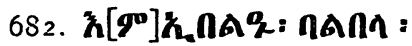

Das $\boldsymbol{q}^{\circ}$ fehlt im MS.

683. K90\%.7-nL: AnR.7:

684. ћF'

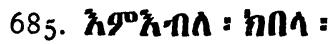

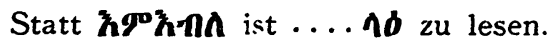

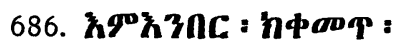

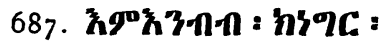

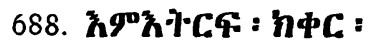

689. h90 h-nhd : han :

Statt $\boldsymbol{h \Pi n}$ ist $\boldsymbol{h} . \mathrm{zu}$ lesen.

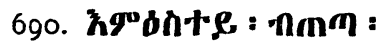

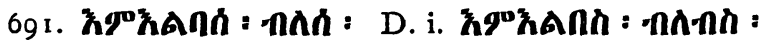

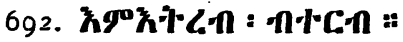

Im Ge'ez ist I Ln oder FCa nicht belegt. In Am- 
harischen heisst $+\angle \|$ sderidere, canzonarę, im Tigriña »parlare sentenziosamentec; im Tigrẻ ist $\boldsymbol{H C h}=$ ıerreissen «.

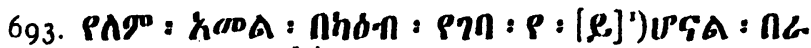

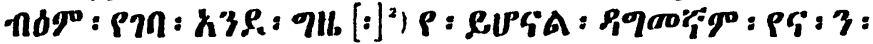

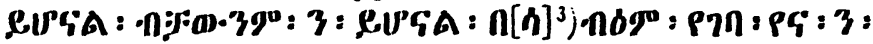
RUPGA : nF:D.go : 3 ' RIPGA :

D. i.: ,Wenn $\Lambda$ gleich nach $k \bar{a}^{t} \partial b(\bar{n})$ steht, ist es $=$

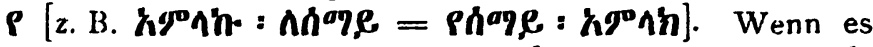

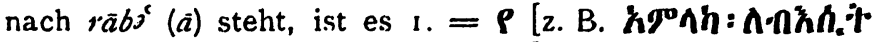

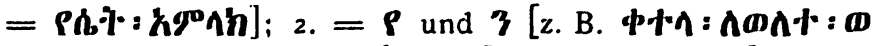
A.

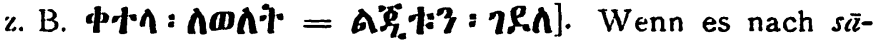
$6 \delta^{c}(\bar{o})$ steht, so wird es $1 .=\rho$ und $\boldsymbol{z}\left[\begin{array}{ll}2 & B\end{array}\right.$

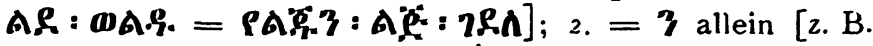

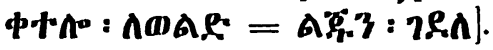

Das Verständnis dieser Stelle verdanke ich Herrn Prof. I. Guidi.

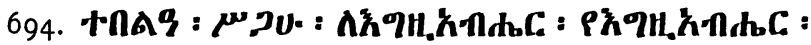

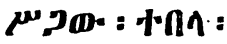

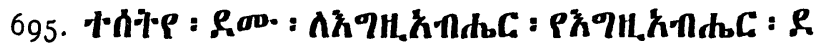
ob. : Tmm :

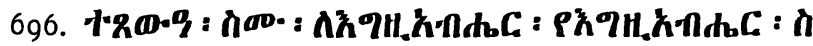
ob. : 12k: :

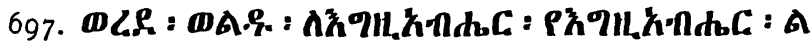
\% : a CR:

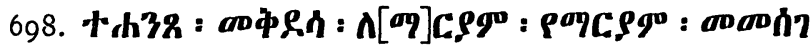
ร甲: Thl. :

Im dritten Worte steht in der Kopie ein $\boldsymbol{g}^{\mathbf{D}}$ mit einem Fragezeichen. Im fünften Worte ist wohl h statt $\boldsymbol{h} z \mathrm{zu}$ lesen. Das amharische Wort findet sich in der Bedeutung "Heiligtum« nicht bei Guıdr.

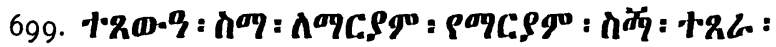
1) Kopie $\boldsymbol{\rho}$.
2) Kopie om.
3) Kopie $\boldsymbol{h}$. 


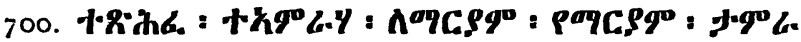
I: : 186.:

Im zweiten Worte 1. 6 statt 6., im letzten Worte ? statt $\mathbf{R}$.

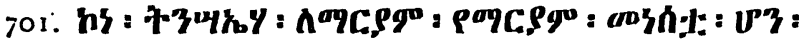

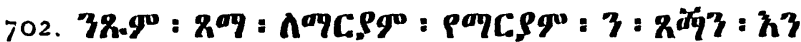
8.90:

Im zweiten und sechsten Worte 1.8 statt $\mathbf{R}$.

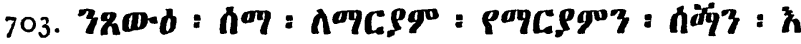
386:

Im zweiten und fünften Worte 1 . h statt $\mathbf{h}$.

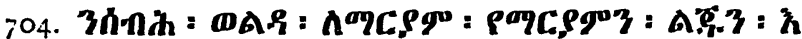
500193:

Statt $A \mathbf{S}_{\mathbf{Z}}$ ist wohl $\mathbf{z}$. zu lesen; im letzten. Worte n statt $\mathbf{n}$.

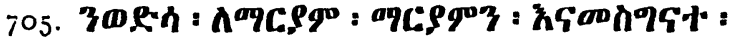

Im letzten Worte 1 . \% statt $\mathbf{T}$.

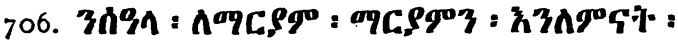

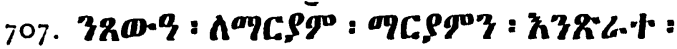

Im letzten Worte 1. ₹ statt + .

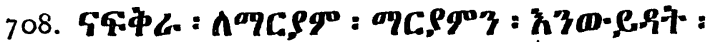

Im letzten Worte 1 . $\boldsymbol{S}$ statt $\boldsymbol{\ell}$.

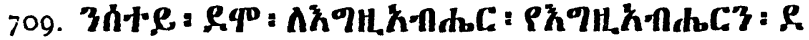
$00.3: \$ 3 m \pi$ :

Im ersten Worte 1 . in statt $\boldsymbol{h}$.

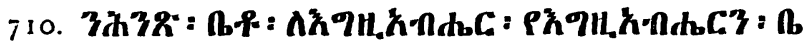

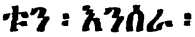

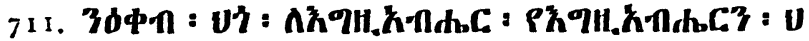
2.3: औ3m-nt :

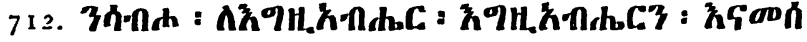
Tha.

Im ersten Worte 1. $\boldsymbol{n}$ statt $\boldsymbol{h}$, im letzten $\boldsymbol{n}$ statt $\boldsymbol{h}$.

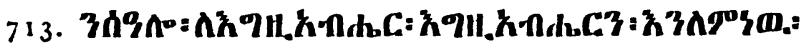




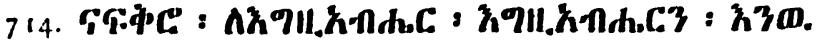
8.8.(1): :

Im letzten Worte 1. $\boldsymbol{D} \cdot$ statt $\boldsymbol{m}$.

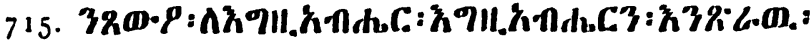
PA3:

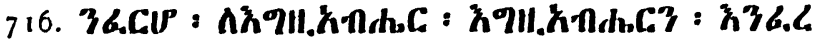

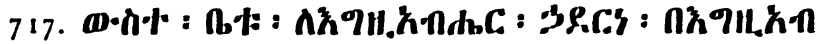
dbC: : An, l: : he.C:3 :

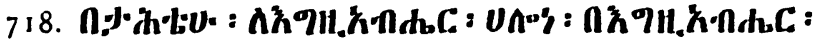

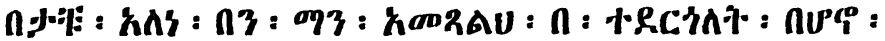
C6.5. A :

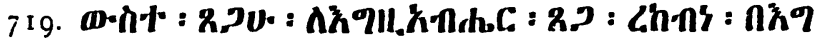
11.h-1h.C : กกลร

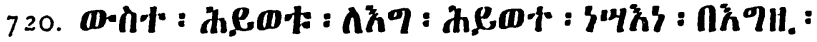

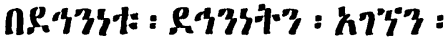

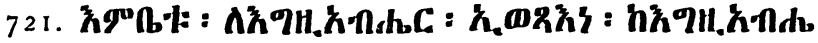

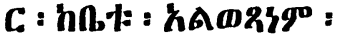

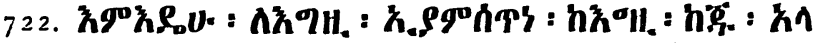

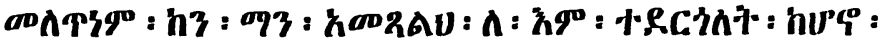

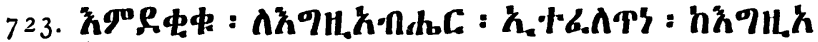

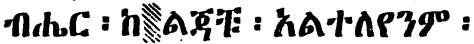

Statt $\bar{\varnothing}$ ist im fünften Worte $\overline{g u}$ lesen.

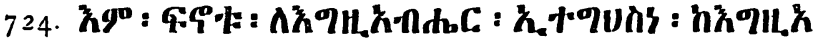

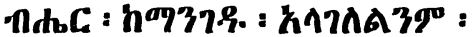

Statt 77 ist im sechsten Worte $\boldsymbol{\sigma 0}$ zu lesen.

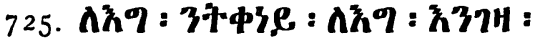

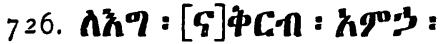

Hier folgt ein leeres Blatt.

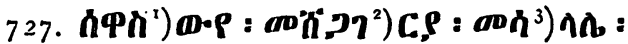

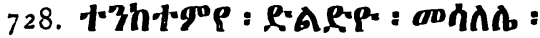

Statt $\boldsymbol{P}$ - ist $\boldsymbol{P} z$ zu lesen.
1) Kopie $\boldsymbol{h}$.
2) Kopie $\mathbf{n}$.
3) Kopie h. 
729. P.QP : ABAP :

730. ODADAWP: ПNP :

731. häP : \$3.8द :

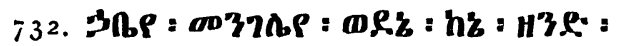

\section{9unse : hל : ח6: :}

Statt MG. ist $36.2 \mathrm{z}$ lesen.

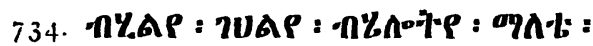

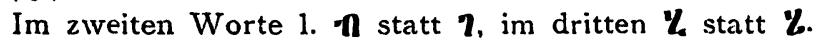

735. H9:P : 8.06.7.P :

Das erste Wort ist R\%.FP zu lesen; das letzte vielleicht morb.

736. $\Lambda_{0}+: \Lambda_{\xi}: \hbar_{b}:$

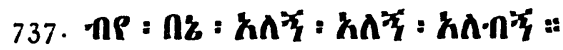

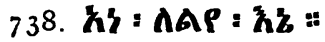

739. H.KP : ћ3t.KP : P夕 :

740. $\hbar, \rho P: \hbar b: 3: ;$

Statt $\boldsymbol{h}, \boldsymbol{P} \boldsymbol{P}$ ist $\mathbf{h}, \boldsymbol{\rho} \boldsymbol{\rho}$ zu lesen. 